\title{
ANÁLISE DA INFLUÊNCIA DE SISTEMAS DE APROVEITAMENTO DE ÁGUAS PLUVIAIS NUMA REDE DE ABASTECIMENTO DE ÁGUA POTÁVEL. O CASO DO LAGO NORTE, BRASÍLIA-DF - BRASIL
}

\author{
ANALYSIS OF THE INFLUENCE OF RAINWATER HARVESTING IN A PUBLIC WATER SUPPLY \\ NETWORK. THE CASE OF LAGO NORTE, BRASÍLIA-DF, BRAZIL
}

Gabriel Barros Dolabellaa, Maria Manuela Carvalho de Lemos Limaa

aUniversidade do Minho

gdolabella@gmail.com,.mmlima@civil.uminho.pt

Submissão: 15 de março de 2021 Aceitação: 1 de julho de 2021

\section{Resumo}

A preocupação com a utilização dos recursos naturais e especialmente com os recursos hídricos é cada vez maior, sendo importante, portanto, o estudo da utilização de fontes alternativas de abastecimento de água e a influência que estas alternativas possam causar aos sistemas tradicionais. O objetivo deste artigo é analisar a influência que a adoção de sistemas de aproveitamento de águas pluviais pode causar numa rede pública de distribuição de água potável, nomeadamente em relação às velocidades, pressões dinâmicas e concentração de cloro residual. Foi realizado um estudo de caso da rede que abastece o bairro do Lago Norte, Brasília-DF, observando-se como resultado das simulações hidráulicas computacionais, utilizando-se o EPANET, a diminuição das velocidades, o aumento das pressões dinâmicas e a diminuição do cloro residual livre à medida em que há aumento do uso de sistemas de aproveitamento de águas pluviais. Por este motivo, este estudo conclui que a monitorização da rede deve ser permanente, visto que há cada vez mais o uso de sistemas alternativos para consumo de água, especialmente após a crise hídrica de 2016/2017, o que pode afetar o fornecimento de água, tanto qualitativamente quanto quantitativamente.

Palavras-chave: Aproveitamento de águas pluviais; Sistemas de aproveitamento de águas pluviais; Sustentabilidade; Rede pública de abastecimento de água

\section{Abstract}

The concern about the use of natural resources and especially about water resources is growing, therefore it is important to study the use of alternative sources of water supply and the influence that these alternatives may have on traditional systems. The objective of this article is to analyze the influence that the adoption of Rainwater Harvesting Systems - RHS - can cause in a public drinking water distribution network, namely in relation to the velocity, dynamic pressures and concentration of residual chlorine. A case study of the network that supplies the Lago Norte neighborhood, Brasilia-DF, was carried out, in which the computational hydraulics simulations, using EPANET, shows a decrease in velocity, an increase in dynamic pressures and a decrease in Free Residual Chlorine - FRC - as there is an increase in use of RHS. For this reason, this study concludes that the monitoring of the network must be permanent, since there is an increasing use of alternative systems for water consumption, especially after the 2016/2017 water crisis, which can affect the water supply both qualitatively and quantitatively.

Keywords: Rainwater harvesting system; Sustainability; RWH; Public Water Supply

\section{INTRODUÇÃO}

De acordo com o Relatório Mundial das
Nações Unidas sobre o Desenvolvimento dos Recursos Hídricos (NAÇÕES UNIDAS, 2018) as necessidades mundiais de água têm crescido a 
uma taxa aproximada de $1 \%$ ao ano, projetando um crescimento acentuado nas próximas duas décadas, principalmente nos países de economias emergentes ou em desenvolvimento. Este aumento é fomentado por diversos fatores, como por exemplo o crescimento populacional, o desenvolvimento econômico e novos padrões de consumo da sociedade contemporânea. Segundo a Organização para a Cooperação e Desenvolvimento Económico (OCDE, 2012) este aumento das necessidades de água foi projetado em 55\% entre os anos de 2000 e 2050.

Esta utilização crescente da água, aliada às alterações climáticas e à necessidade de proteção do meio ambiente sugere que se procure assegurar a confiabilidade de que o abastecimento de água sirva a todos no futuro (ENVIRONMENT AGENCY, 2010). Por outro lado, cerca de $78 \%$ dos empregos existentes a nível mundial são, de alguma forma, dependentes dos recursos hídricos, pelo que a escassez de água terá como consequência provável a limitação do crescimento económico e da criação de emprego (NAÇÕES UNIDAS, 2016). Para além disto, a menor disponibilidade de água tende a agravar a disputa pelo acesso a este recurso por parte dos seus utilizadores, com consequências para a segurança energética e alimentar, e mesmo para a segurança geopolítica, afetando diretamente as migrações em todo o mundo (NAÇÕES UNIDAS, 2016).

A procura da melhoria da qualidade de vida das pessoas e a sua conjugação com o conceito de sustentabilidade resultou parcialmente na adoção dos Objetivos de Desenvolvimento do Milénio - ODM -que deveriam ter sido alcançados no ano de 2015. Apesar de ter havido avanços significativos em relação aos ODM, a pressão sobre as fontes de recursos naturais continuou sendo um grande desafio para que não se comprometesse o futuro das novas gerações, tanto por causa do aumento populacional mundial, quanto pelo aumento da quantidade de resíduos que são rejeitados no meio ambiente, especialmente nos mananciais de água (GONÇALVES, 2009, VIEIRA, 2018). Assim, posteriormente, foram estabelecidos os Objetivos do Desenvolvimento Sustentável - ODS - com prazo até o ano de 2030. Dentre estes novos objetivos, destacam-se os que se referem ao uso racional dos recursos hídricos, mais especificamente ao aproveitamento de águas pluviais, que se enquadra assim nos objetivos 6 , 11 e 13 - Água Potável, Cidades e Comunidades Sustentáveis, e Ação Contra a Mudança Global do
Clima, respectivamente (VIEIRA, 2018).

Assim se conclui que há necessidade de utilizar a água de uma forma eficiente e sustentável. De entre os métodos mais utilizados atualmente, com vista à melhoria da eficiência em relação ao uso da água, podem citar-se: a redução do consumo de água, a redução das perdas nos sistemas públicos de abastecimento de água e o aproveitamento de água proveniente de fontes alternativas, como a utilização de água dos oceanos, a reutilização de águas residuais tratadas e o aproveitamento de águas pluviais (TEXAS COMMISSION ON ENVIRONMENTAL QUALITY, 2007).

O aproveitamento de águas pluviais é a prática de coletar a água proveniente das chuvas antes que esta chegue aos meios hídricos (rios, lagos, etc.) ou antes que se infiltre no solo e seja então considerada como água subterrânea (TEXAS COMMISSION ON ENVIRONMENTAL QUALITY, 2007). Após a coleta, a água pluvial é armazenada para posterior utilização para fins não potáveis, por exemplo na irrigação de jardins, na lavagem de roupas e na descarga de bacias sanitárias (ENVIRONMENT AGENCY, 2010). Segundo a American Water Works Association (AWWA) (1999), uma residência típica de clima quente estadunidense possui um potencial de redução de consumo de água, se utilizados Sistemas de Abastecimento de Águas Pluviais (SAAP), de aproximadamente $80 \%$, enquanto uma residência típica localizada numa região de clima frio tem um potencial próximo de $64 \%$ de economia, quando se recorre ao aproveitamento de águas pluviais. No Reino Unido este potencial diminui para 45\% (ENVIRONMENT AGENCY, 2010).

O aproveitamento de águas pluviais é utilizado desde pelo menos 3000 a.C., conforme registos encontrados na ilha de Creta, localizada na Grécia (ANTONIOU, KATHIJOTES, et al., 2014). Apesar de nunca ter caído em desuso, houve uma diminuição da sua utilização ao longo dos séculos, especialmente após a introdução dos sistemas públicos de abastecimento de água para consumo humano, a partir do período da I Revolução Industrial (ANTONIOU, KATHIJOTES, et al., 2014). Entretanto, há uma tendência de aumento da utilização de água das chuvas para o consumo humano, tanto pela escassez de água em algumas regiões, como por questões relacionadas com o desenvolvimento sustentável e com as alterações climáticas (ABU-ZREIG, HAZAYMEH, et al., 2013, ANTONIOU, 
KATHIJOTES, et al., 2014, JUUTI, KATKO, et al., 2007).

Os sistemas de aproveitamento de águas pluviais podem ser centralizados, correspondentes à coleta e abastecimento a um bairro ou zona urbana, ou descentralizados, isto é, domésticos, em que cada edifício tem o seu próprio sistema de coleta e abastecimento (SLYS \& STEC, 2020). Este último sistema tem a vantagem de poder ser facilmente instalado e ser independente do investimento público.

Um Sistema de Aproveitamento de Águas Pluviais (SAAP) doméstico é composto, basicamente, por: superfície de coleta, calhas, tubos de queda, dispositivo de desvio de primeiro fluxo (first-flush), pré-filtro e reservatório. Neste caso a superfície de coleta é usualmente o telhado das habitações, sendo a água recolhida pelas calhas e conduzida pelos tubos de queda até ao reservatório, passando antes pelo pré-filtro. O firstflush está ligado aos tubos de queda, e serve para rejeitar as primeiras águas recolhidas após o início da precipitação, já que usualmente podem estar contaminadas pelos detritos acumulados no telhado e nas próprias calhas. O pré-filtro, por sua vez, tem como finalidade reter substâncias não desejadas de maiores dimensões, como folhas e insetos maiores (TEXAS COMMISSION ON ENVIRONMENTAL QUALITY, 2007).

Como o reservatório é, em regra, o elemento de custo mais elevado num SAAP (MUÑOZ, 2017), o seu correto dimensionamento é essencial para o aumento da utilização destes sistemas. Em regiões onde a precipitação ao longo do ano não é um fator limitativo, o volume do reservatório deve ser igual ao consumo potencial de água das chuvas, para que se tenha um melhor aproveitamento deste sistema. Já em regiões onde haja escassez de água em algum período do ano, deve-se levar em conta, para o cálculo desse volume, a área de contribuição da cobertura e a precipitação local (ABU-ZREIG, HAZAYMEH, et al., 2013, ENVIRONMENT AGENCY, 2010, MUÑOZ, 2017). Apesar de, em regra, não ser financeiramente vantajoso instalar um SAAP em zonas onde há fornecimento de água potável por meio de um sistema público de tratamento e distribuição, em zonas onde não há esta facilidade, a utilização de um SAAP pode ser competitiva, comparativamente à instalação de poços em áreas rurais, por exemplo. Outro fator que pode evitar um custo ainda maior em relação à instalação de um SAAP é a inclusão deste sistema no projeto de construção do edifício, evitando-se custos extra com adaptações e com obras de reabilitação (MUÑOZ, 2017, WATER, BOARD, 2005).

A utilização de SAAP acarreta diversos benefícios tais como a redução da pressão sobre os meios de abastecimentos tradicionais, a redução da fatura de água para os utilizadores e a redução do risco de enchentes e de poluição dos meios hídricos, já que parte da água da chuva fica retida nestes sistemas (ENVIRONMENT AGENCY, 2010). Apesar do elevado período de retorno do investimento num SAAP em muitas regiões, há uma tendência de aumento das tarifas de água praticadas pelas entidades gestoras dos sistemas públicos de abastecimento de água, o que pode aumentar a viabilidade financeira daqueles sistemas (SACADURA, 2011).

Uma questão que se tem revestido de maior importância, quando se trata de assuntos como a água e o saneamento, é o aquecimento global. Com a maior incidência de eventos climáticos extremos em diversas regiões do planeta especialmente nas zonas tropicais, tornando a oferta de água cada vez mais difícil de se prever e gerir (MARENGO, 2007) - é necessário que a gestão dos sistemas de abastecimento e de saneamento consiga lidar com estas mudanças. Isto inclui a integração de sistemas, como a redução do consumo de água potável por meio do aproveitamento de águas pluviais, gerando economia de água e energia, concomitante à diminuição do impacto de eventos de grande pluviosidade no caso de inundações (DEITCH, FEIRER, 2019). Nesse contexto de desafios atuais e futuros, que envolvem a utilização da água em todo o planeta, apesar de não parecer haver uma única solução que possa resolvê-los, os SAAP afiguram--se como parte da solução. No entanto, a massificação do uso de SAAP pode acarretar alterações nos valores referentes a alguns parâmetros do funcionamento de uma rede de abastecimento público de água, podendo originar um serviço público de menor qualidade para parte dos utilizadores. Entre estes parâmetros podem-se destacar: as velocidades mínimas e máximas nas tubulações, as pressões estática e dinâmica nos nós das redes e a concentração de cloro residual livre $(C R L)$ na torneira do consumidor. Todos estes parâmetros são definidos em norma ou decreto-lei, sendo, portanto, de cumprimento obrigatório (DOLABELLA, 2019).

Assim, este artigo tem como objetivo geral avaliar a influência que o aumento do uso de SAAP poderia ter sobre as infraestruturas de abastecimento de água potável, por meio de um 
estudo de caso num bairro com grande potencial para o uso deste tipo de sistema - o Lago Norte em Brasília, no Distrito Federal - Brasil. Este estudo foi realizado por meio de simulações EPANET do funcionamento da rede de abastecimento público de água para três cenários diferentes, em que se consideraram volumes de água da chuva aproveitada distintos. Por meio destas simulações foi possível analisar possíveis mudanças nas pressões das tubulações da rede de abastecimento, assim como alterações nas velocidades da água nestas tubulações, e ainda analisar possíveis alterações de CRL no sistema, o que poderia acarretar alterações da qualidade da água fornecida à população, caso haja aumento significativo de uso de SAAP.

\section{IMPACTOS DOS SAAP NAS INFRAESTRUTURAS DE SANEAMENTO BÁSICO}

As infraestruturas de saneamento básico constituem um elemento fundamental do que é a garantia de um direito humano - o direito à água potável e ao saneamento básico (NAÇÕES UNIDAS, 2015). No entanto, estas estruturas são sistemas complexos, que devem assegurar um serviço público universal, essencial, contínuo e de qualidade (ALEGRE \& COVAS, 2010). No entanto, a promoção da adoção generalizada de SAAP pode acarretar impactos nas infraestruturas de saneamento básico, em especial nas redes de abastecimento público de água. No texto que se segue apresenta-se uma descrição sucinta destes impactos nas infraestruturas de saneamento básico, organizados nas suas vertentes financeira e/ou económica, ambiental e técnica.

Um bom exemplo da dicotomia vantagem/desvantagem é a visão da economia na fatura de conta de água decorrente da utilização de água proveniente de um SAAP residencial. $\mathrm{Na}$ óptica do consumidor pode ser absolutamente benéfica, enquanto, para a empresa responsável pelo abastecimento público de água, a possível redução de receitas devidas ao menor consumo de água proveniente do sistema público pode ter um impacto negativo na sua gestão financeira. $O$ aumento do uso de SAAP pode acarretar mudanças metodológicas de cobrança pelos serviços de abastecimento, por exemplo no caso em que a água da chuva aproveitada seja utilizada e rejeitada como água residual na rede pública de drenagem. Como normalmente o valor cobrado pelo serviço de drenagem de águas residuais é feito tendo por base o volume de água de abastecimento público consumida na habitação, o usuário poderia deixar de ser cobrado pelo volume efetivo rejeitado para a rede de drenagem de águas residuais, acarretando possíveis prejuízos à entidade gestora responsável por este serviço. Por outro lado, a utilização de água pluvial para fins menos nobres possibilita uma redução dos custos associados à captação e ao tratamento de água em Estações de Tratamento de Água (ETA). O custo associado ao transporte de água até ao consumidor final também é parcialmente reduzido, pois a água pluvial está disponível in situ, e o menor consumo de água a partir da rede pública corresponderá a menores perdas de carga e de energia associada (DOLABELLA, 2019).

No que diz respeito à vertente ambiental considera-se uma vantagem a preservação de mananciais de água, já que menos corpos de água precisariam ser utilizados para captação de água para abastecimento público, enquanto que uma possível desvantagem é a menor quantidade de água disponível para a recarga dos aquíferos, já que volumes significativos de água da chuva seriam retidos em reservatórios, concorrendo assim para a diminuição de infiltração que já tem a sua ação prejudicada pelo aumento da impermeabilização do solo, especialmente nas grandes cidades. Coombes e Kuczera (2003) afirmam que a poupança de água relativa à implementação massiva de SAAP na Austrália pode gerar $o$ adiamento da necessidade de implementação de novas albufeiras naquele país (apud GRANDET et al., 2010).

Por outro lado, o uso de SAAP pode evitar que eventos de pluviosidade intensa, que ocorrem em pequenos intervalos de tempo, provoquem danos como cheias e inundações, auxiliando na diminuição do escoamento superficial, que é um fator determinante para os problemas relacionados com esses eventos. Um caso de estudo realizado por DEITCH \& FEIRER (2019) na Flórida, nos Estados Unidos da América, mostrou ser possível reduzir o caudal na rede de drenagem em mais de $20 \%$ para um evento de pluviosidade com período de retorno de 1,5 anos, quando os SAAP são amplamente utilizados em áreas residenciais. Assim, isto traduz-se numa influência positiva para a entidade gestora de uma rede de drenagem de águas pluviais. $\mathrm{O}$ Quadro 1 sumariza as consequências financeiras e ambientais que a utilização em larga escala de SAAP poderia acarretar.

Desta forma, é possível salientar que esta 
vertente ambiental se conjuga igualmente com a vertente técnica, que assume especial relevância no presente trabalho. O Quadro 1 sumariza igualmente as consequências técnicas que a utilização em larga escala de SAAP poderia acarretar. O uso generalizado de SAAP poderia auxiliar na redução dos diâmetros dos coletores em sistemas de drenagem do tipo unitário, devido à redução do caudal a escoar, pelo menos parcialmente, durante o período chuvoso (DEITCH, FEIRER, 2019) Para além disto, estas redes de drenagem unitárias deixariam de estar sujeitas, pelo menos em parte, à elevada variabilidade decorrente do facto de drenarem águas residuais e pluviais.

\section{Quadro 1: Consequências do uso generalizado de SAAP (DOLABELLA, 2019)}

\begin{tabular}{|c|c|c|}
\hline Vertente & Eventos & Possíveis consequências \\
\hline Financeira & Custos do serviço & $\begin{array}{l}\text { Não contabilização na cobrança dos serviços de águas } \\
\text { residuais } \\
>\text { Redução dos custos com material em função da diminuição do } \\
\text { diâmetro das tubulações } \\
>\text { Redução dos custos de captação de água para produção de } \\
\text { água para consumo humano } \\
>\text { Redução do volume de água para consumo humano tratada em } \\
\text { ETA, correspondente a uma redução de custos } \\
>\text { Redução dos custos com transporte de água para consumo } \\
\text { humano }\end{array}$ \\
\hline Ambiental & Ciclo da água & $\begin{array}{l}>\text { Redução da recarga dos aquíferos } \\
\text { Menores consequências em razão de chuvas intensas, } \\
\text { especialmente em áreas urbanas altamente impermeabilizadas }\end{array}$ \\
\hline \multirow[t]{3}{*}{ Técnica } & $\begin{array}{l}\text { Alteração de pressão nos nós e } \\
\text { nas tubulações }\end{array}$ & $\begin{array}{l}>\text { Incumprimento dos valores regulamentares de pressão na rede } \\
>\text { Rompimento de tubulações } \\
>\text { Danos nos aparelhos hidráulicos (válvulas, hidrómetros, etc.) }\end{array}$ \\
\hline & $\begin{array}{l}\text { Alterações na velocidade da } \\
\text { água na rede }\end{array}$ & $\begin{array}{l}\text { Incumprimento dos valores regulamentares de velocidade na } \\
\text { rede } \\
>\text { Aumento do tempo de vida da água na rede } \\
>\text { Alterações da qualidade da água - diminuição do CRL } \\
>\text { Sedimentação de partículas e formação de biofilmes no interior } \\
\text { das tubulações }\end{array}$ \\
\hline & $\begin{array}{l}\text { Alteração da concentração de } \\
\text { CRL }\end{array}$ & $\begin{array}{l}>\text { Incumprimento dos valores regulamentares de CRL na rede } \\
>\text { Alteração das características organoléticas } \\
>\text { Presença de contaminantes na água } \\
>\text { Redução da segurança em relação à qualidade da água }\end{array}$ \\
\hline
\end{tabular}

Nas infraestruturas de abastecimento de água como fornecedoras de um serviço público de qualidade (GRANDET, BINNING, et al., 2010) percebe-se que os SAAP não devem ser levados em conta como fontes de abastecimento confiáveis, pois a infraestrutura de produção e distribuição de água centralizada deve ser projetada para atender a picos de consumo, incluindo uma redundância em relação aos SAAP em caso de um período de seca prolongado (GRANDET, BINNING, et al., 2010). Além disso, uma análise à escala anual não é adequada para ser utilizada em relação aos efeitos gerados nas redes de produção e de distribuição de água, posto que estas redes são dimensionadas para suportar picos de consumo diário ou mesmo horário (GRANDET, BINNING, et al., 2010). Outra questão é que o dimensionamento dos diâmetros das tubulações segue as normas de prevenção de incêndios e não unicamente de picos de consumo doméstico, ou seja, adaptar a tubulação de toda a rede para menores consumos implicaria uma mudança na estratégia de combate a incêndios, que não dependesse da pressão dinâmica e do caudal disponível no sistema público (GRANDET, BINNING, et al., 2010). Assim, e considerando que a adopção generalizada de SAAP não deverá alterar os critérios de dimensionamento de redes de abastecimento público de água, terá obrigatoriamente que acarretar consigo a definição 
de práticas de gestão e exploração das redes de abastecimento de água, para que as normas legais em vigor possam continuar a ser atendidas.

Com o aumento do uso de sistemas alternativos de abastecimento de água, alguns parâmetros predeterminados por norma podem não ser atingidos, como os valores de pressão mínima e máxima nos nós da rede pública de abastecimento de água, as velocidades mínimas e máximas nas tubulações.

O estudo das pressões dinâmicas e estáticas é importante porque pressões muito pequenas podem acarretar dificuldade de abastecimento de algumas áreas, principalmente as de maior cota topográfica, além de aumentar a probabilidade de contaminação da água no interior das tubulações, caso estas sofram alguma ruptura. Já pressões muito elevadas podem danificar as tubulações e equipamentos hidráulicos.

O controle da velocidade nas tubulações é importante para garantir que não há desgaste excessivo das tubulações (velocidades muito elevadas) e para garantir que não haja degradação da qualidade de água (velocidades muito baixas) como a que pode ocorrer por deposição de sedimentos, por exemplo. Por outro lado, a limitação máxima da velocidade tem como objetivos diminuir a perda de carga no transporte da água até ao consumidor final, bem como evitar sobrepressões em razão do Golpe de Aríete, os ruídos excessivos e o desgaste das tubulações e dos equipamentos. Apesar deste último parâmetro ter sido retirado na última atualização da NBR 5626:2020, este parâmetro foi considerado neste estudo.

O uso em larga escala de SAAP pode igualmente influenciar a qualidade da água em função da alteração gerada na idade da água, já que, com a redução do caudal escoado, a água tenderia a permanecer mais tempo no sistema de distribuição (GRANDET, BINNING, et al., 2010). A idade da água é um importante indicador do risco de contaminação bacteriológica, e a maior causa de ocorrência de problemas relacionados com a qualidade da água no sistema de distribuição está relacionada com o crescimento bacteriológico. Com o aumento da idade da água observa-se a diminuição da concentração de desinfetante residual livre, usualmente o cloro residual livre CRL- que evita a recontaminação da água na rede de abastecimento e garante a segurança para a saúde pública. O cloro tem, atualmente, grande importância no tratamento da água, sendo utilizado em todo o mundo como desinfetante, por atender a critérios de qualidade e eficiência como baixa toxicidade, solubilidade, eficácia quando em temperaturas entre $0^{\circ}$ e 25으, facilidade de manipulação, preço e quantidade acessível. Além disso, o cloro utilizado no processo de desinfeção possui estabilidade, mantendo concentrações residuais ao longo do tempo. No entanto a utilização do cloro no processo de desinfeção pode acarretar elementos nocivos à saúde humana, quando combinado com substâncias orgânicas, formando os compostos organoclorados (VIEIRA, 2018).

Para evitar a formação de subprodutos da desinfeção (SPD) alguns fatores devem ser controlados, como a temperatura e o pH da água, bem como o controle da dose a ser utilizada, o tempo de vida da água na rede e o tempo de contato entre a água e o desinfetante.

A título de exemplo, referem-se os valores preconizados pela legislação em vigor no Brasil. A NBR ABNT 12218 (2017) determina que as pressões estáticas não devem ultrapassar $400 \mathrm{kPa}$ (ou 40,78 mca), admitindo-se chegar a $500 \mathrm{kPa}$ (ou $50,97 \mathrm{mca}$ ) em regiões de topografia acidentada, enquanto as pressões dinâmicas não devem ser menores do que $100 \mathrm{kPa}$ (ou 10,19 mca). Estes valores máximos e mínimos de pressão são determinados para os trechos em que há ligação direta aos consumidores ou em tubulações secundárias, sendo necessário que se garanta, entretanto, a estabilidade estrutural e a segurança sanitária nos demais trechos. Conforme a NBR ABNT 12218 (2017) a velocidade da água nas tubulações não pode ser menor do que $0,4 \mathrm{~m} / \mathrm{s}$, enquanto a velocidade máxima deve ser a correspondente a uma perda de carga máxima de $10 \mathrm{~m} / \mathrm{km}$. A segurança dos usuários do sistema de abastecimento público em relação à potabilidade da água é estabelecida pela Portaria de Consolidação ํo 5/2017 do Ministério da Saúde (MS), que define a manutenção mínima de CRL igual a $0,2 \mathrm{mg} / \mathrm{L}$ ou então a concentração de 2,0 $\mathrm{mg} / \mathrm{L}$ de cloro residual combinado (CRC), podendo ainda manter-se $0,2 \mathrm{mg} / \mathrm{L}$ de dióxido de cloro $\left(\mathrm{ClO}_{2}\right)$ ao longo de toda a extensão do sistema de distribuição de água. Por outro lado, as concentrações máximas de CRL não devem ser superiores a $2,0 \mathrm{mg} / \mathrm{L}$ em nenhum ponto do sistema de abastecimento (MINISTÉRIO DA SAÚDE DO BRASIL, 2017).

Foram assim identificados novos desafios no que diz respeito à concepção e exploração dos sistemas públicos de abastecimento de água. Independentemente de serem considerados 
vantajosos ou desvantajosos, por quem quer que seja, a análise dos impactos causados pelo uso em escala de sistemas alternativos de abastecimento de água deve ser sempre feita, fornecendo aos stakeholders informação para que sejam tomadas as melhores decisões em relação à utilização destes sistemas.

\section{METODOLOGIA}

\subsection{Caracterização da área de estudo}

Com o objetivo de quantificar os impactos técnicos numa rede pública de abastecimento de água decorrentes da adoção generalizada de SAAP, estudou-se o comportamento hidráulico e em termos de qualidade de água, da rede de abastecimento de água da Região Administrativa (RA) do Lago Norte, localizada na cidade de Brasília, no Distrito Federal (DF) (Figura 1).

A RA Lago Norte é considerada uma região com elevado poder aquisitivo (renda alta), com grandes áreas por cada lote (1364 $\mathrm{m}^{2}$ em média) e com elevado consumo de água per capita (321 L/hab./dia em média) e portanto com grande potencial de utilização de SAAP (SANT'ANA, MEDEIROS, et al., 2017). Este bairro possui características típicas de área residencial, com um número elevado de piscinas e grandes áreas de relvado, além de grandes áreas de cobertura - o que aumenta o potencial de captação de água das chuvas.

Figura 1: Mapas do Brasil, do DF e do Lago Norte

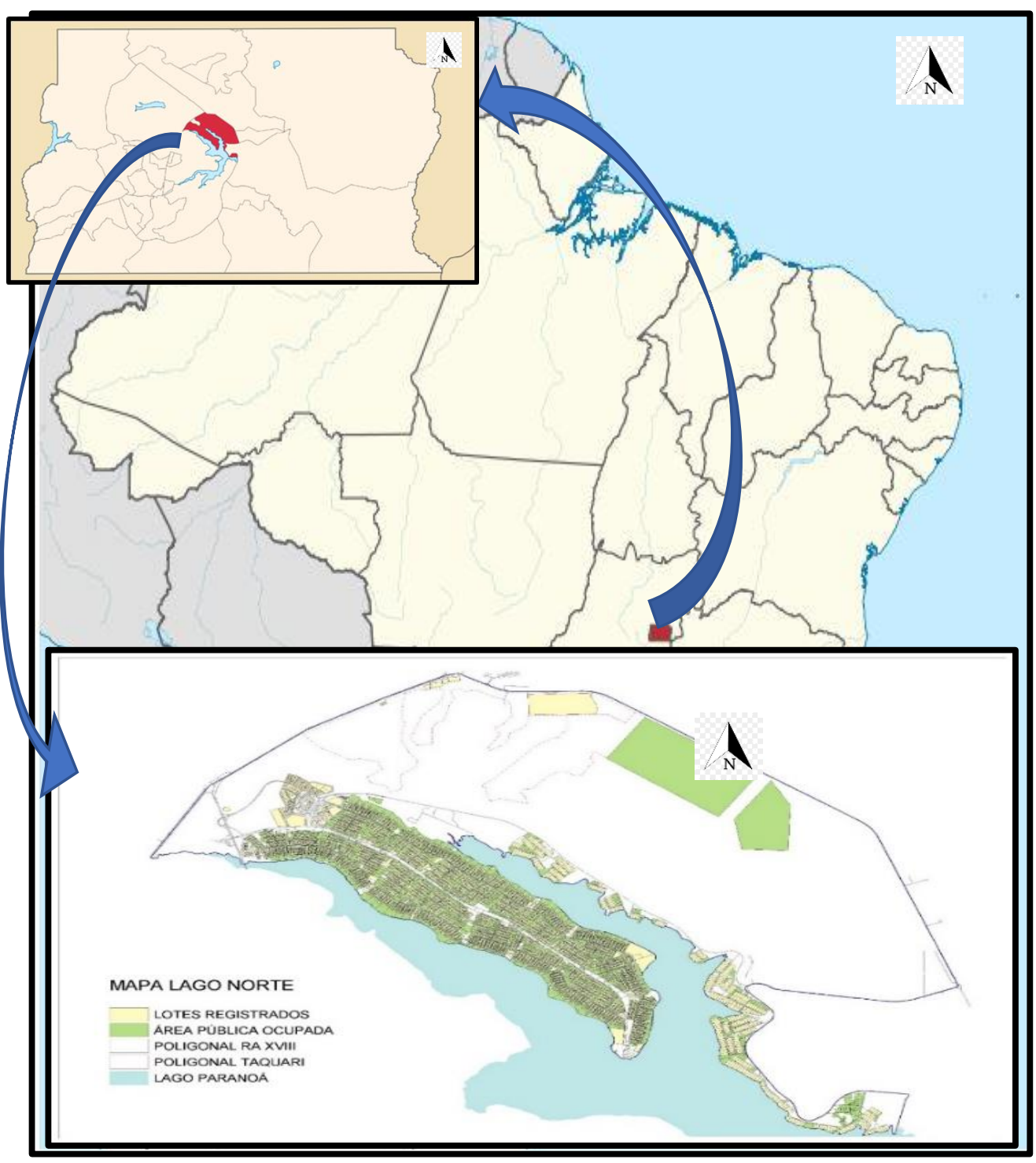

(ADMINISTRAÇÃO REGIONAL DO LAGO NORTE, 2016, WIKIPEDIA, 2019) 
O regime de chuvas na região tem como característica a alternância entre meses quentes e chuvosos (entre maio e setembro) e meses frios e secos (entre outubro e abril), conforme a Figura 2. De acordo com o Instituto Nacional de Meteorologia - INMET - (2019) a precipitação mensal média entre os anos de 1962 e 2018 no DF foi de $124,4 \mathrm{~mm}$, enquanto quando se considera o período seco do ano - de maio a setembro - a precipitação média entre 1962 e 2018 foi igual a
21,6 mm. Já no período chuvoso - entre outubro e abril - o valor médio da precipitação mensal foi igual a 201,3 mm. Como consequência da caraterística pluviométrica da região e por ser um local distante do oceano ou de outras grandes massas de água, também se observa grande discrepância em relação à humidade relativa do ar, sendo comum o registo na estação seca de humidades relativas do ar abaixo de $30 \%$.

Figura 2: Precipitação acumulada mensal no DF entre 2010 e 2019

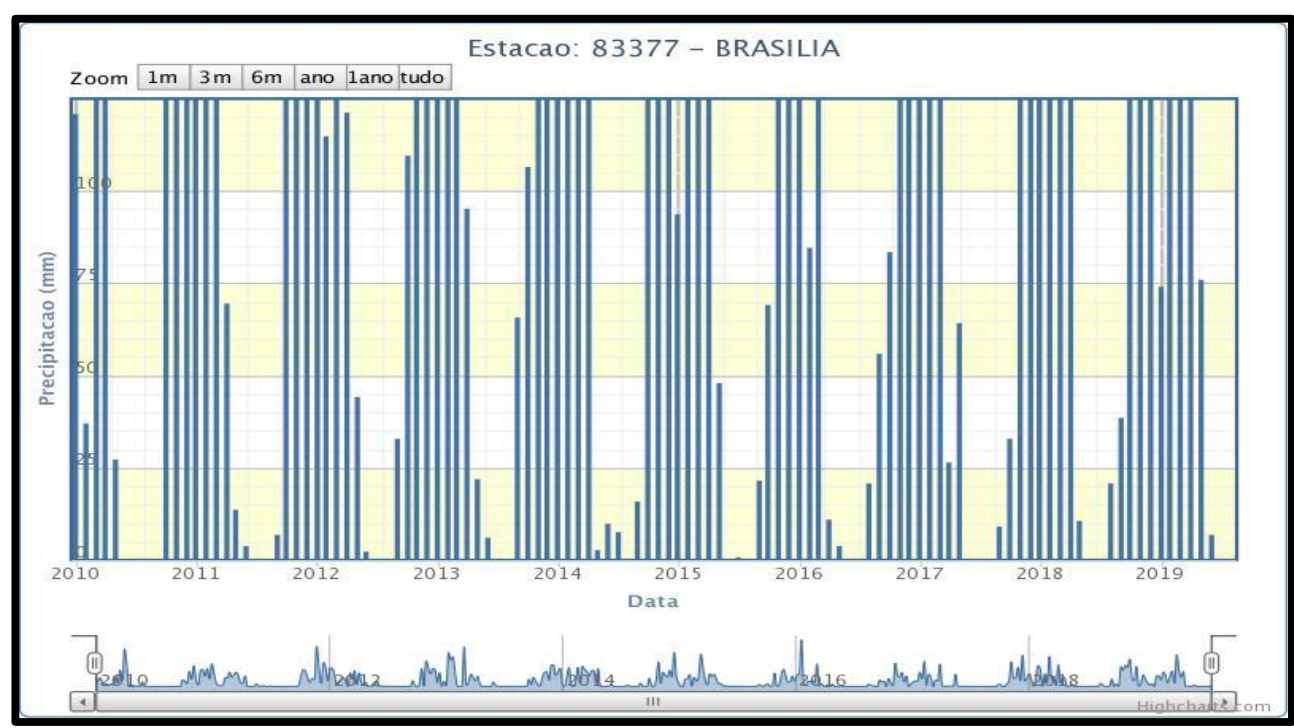

(INMET, 2019)

Esta característica climática aliada aos problemas relacionados ao crescimento populacional acelerado, ao crescimento desordenado das cidades, ao investimento deficiente em infraestruturas de saneamento básico e às mudanças nos regimes das chuvas, tem causado falta de água nos períodos secos, inclusive com a adoção de racionamento de água por meio de rodízio de abastecimento entre janeiro de 2017 e junho de 2018 (AGÊNCIA BRASíLIA, 2018).

O bairro do Lago Norte é abastecido com água proveniente ETA do Lago Norte, que foi construída justamente após a crise hídrica do período entre os anos de 2016 e 2018, e foi concebida para que houvesse um novo ponto de captação de água - o lago Paranoá - que até então não era utilizado como fonte de captação de água para abastecimento público. Esta ETA foi a primeira instalado no DF com sistema compacto de tratamento utilizando a técnica de ultrafiltração por membranas, tornando-se referência não só no
DF como em todo o Brasil (AGÊNCIA BRASÍLIA, 2018).

\subsection{Cenários}

Foi simulado o comportamento hidráulico e de qualidade da rede recorrendo ao software EPANET, versão 2.00.12.01, na língua inglesa, obtido pelo sítio eletrônico da Agência de Proteção Ambiental (Environment Protection Agency) dos Estados Unidos da América, obtendo-se os valores das velocidades (máxima e mínima) nas tubulações, das pressões dinâmica e estática, e da concentração de CRL para três cenários diferentes.

Consideraram-se os potenciais máximos de redução de consumo de água da rede pública de abastecimento, levando em conta o fator financeiro e o maior volume aproveitável de água. As zonas de renda alta (da qual o Lago Norte faz parte) possuem um potencial de redução do consumo de água potável por meio dos SAAP de 43,0\% (229 
$\mathrm{m}^{3} /$ residência/ano). Como parâmetro de análise financeira foi levado em conta o Valor Presente Líquido (VPL) relacionado com o investimento necessário para a instalação e manutenção de um SAAP, de acordo com o estudo realizado por SANT'ANA et al., (2017).

Os cenários foram definidos utilizando-se dados sobre o potencial de aproveitamento de água por meio da utilização de SAAP, tendo sido determinados os cenários em que não haveria utilização de SAAP na região - Cenário 1 ; 0 cenário em que todos os usuários do sistema público de abastecimento utilizariam reservatórios de $50 \mathrm{~m}^{3}$ de volume (maior volume de armazenamento com VPL positivo) - Cenário 2; e o cenário em que os reservatórios utilizados por todos os usuários do sistema apresentam um volume de $80 \mathrm{~m}^{3}$ (maior volume de armazenamento, independente do VPL) - Cenário 3 (SANT'ANA, MEDEIROS, et al., 2017)

A rede utilizada para realizar as simulações foi fornecida por LOURENÇO (2017), e é uma adaptação da rede, fornecida inicialmente pela Companhia de Saneamento Ambiental do Distrito Federal (CAESB) em formato shapefile, para 0 formato inp. Feita a conversão, foram adotadas as simplificações e adaptações na rede por (LOURENÇO, 2017) com o intuito de fazer com que a rede pudesse ser utilizada no EPANET sem a ocorrência de erros.

Devido ao seu tamanho e quantidade de nós, a simplificação feita por LOURENÇO (2017) considerou que apenas um nó por cada rua representaria a soma dos consumos das moradias dessas ruas. A rede simplificada utilizada nas simulações com os consumos-base definidos está representada na Figura 3 . Os valores dos consumos-base e as características de cada cenário são apresentados no Quadro 2.

O Quadro 3 mostra os parâmetros utilizados para realizar as simulações no EPANET, durante um período total de 168 horas, ou seja sete dias, e o passo de tempo padrão considerado foi de uma hora, para que se pudesse verificar os parâmetros de análise considerando-se a variação de consumo ao longo do dia, conforme o padrão de consumo da Figura 4. Utilizou-se o padrão de consumo da cidade de São Paulo, já que não foi encontrada uma curva para o Distrito Federal (LOURENÇO, 2017). Pela análise deste padrão, nota-se que o consumo de água aumenta pela manhã, atingindo um pico em torno das 13 horas. Durante o período vespertino, nota-se uma queda do consumo, até uma certa estabilidade ao fim do dia e início da noite - até por volta das 20 horas, quando se inicia uma nova queda de consumo até chegar a um mínimo por volta das 4 horas.

Figura 3: Consumo-base dos nós da rede simplificada

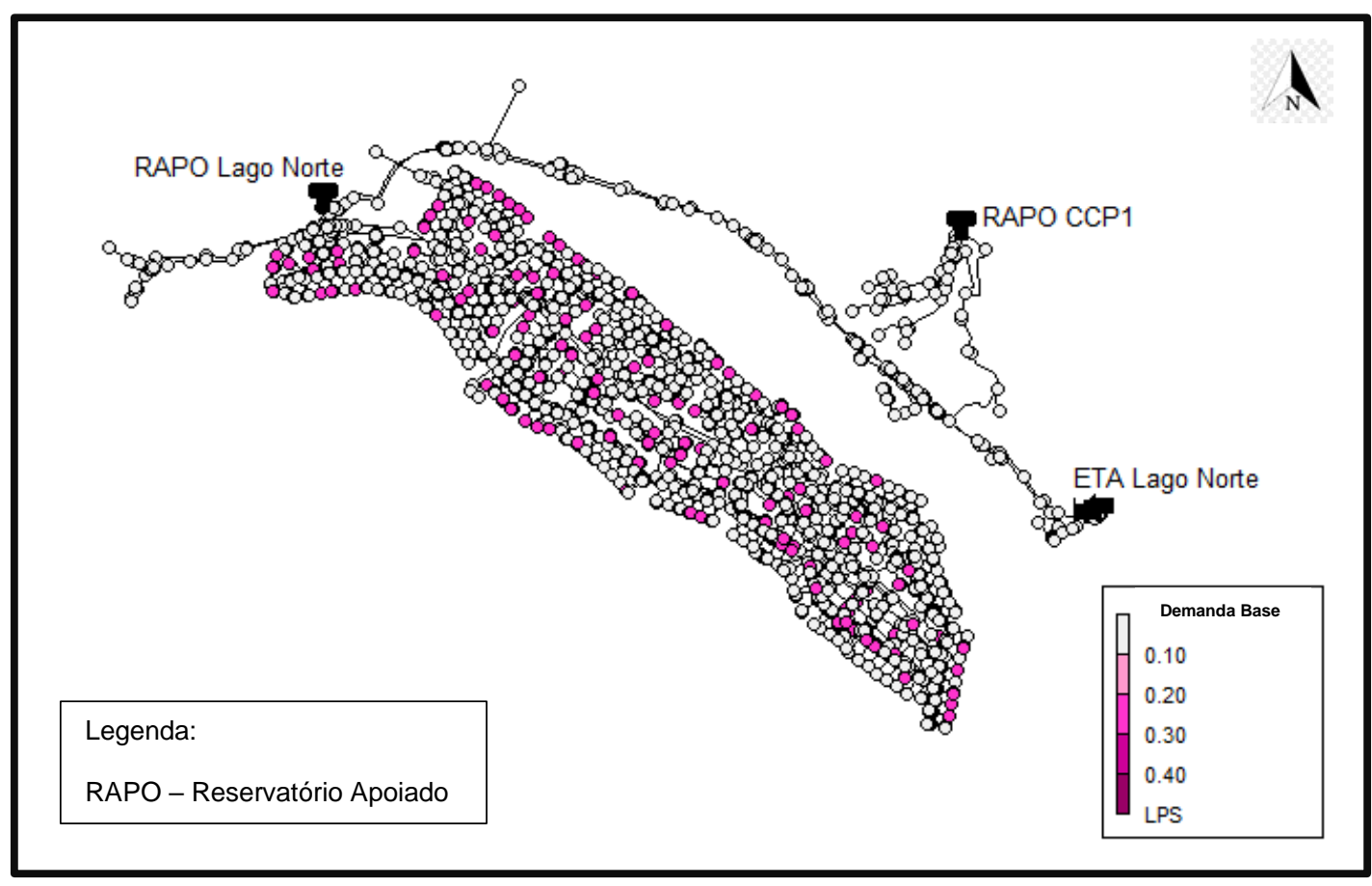

(DOLABELLA, 2019) 
Quadro 2: Cenários adotados para as simulações

\begin{tabular}{|c|c|c|c|l|}
\hline \begin{tabular}{c} 
Cenário \\
\hline 1
\end{tabular} & $\begin{array}{c}\text { Volume do } \\
\text { reservatório } \\
\left(\mathbf{m}^{3}\right)\end{array}$ & $\begin{array}{c}\text { Redução de } \\
\text { consumo da } \\
\text { rede de } \\
\text { abastecimento } \\
(\%)\end{array}$ & $\begin{array}{c}\text { Consumo- } \\
\text { base por nó } \\
\text { (LPS) }\end{array}$ & \multicolumn{1}{c|}{ Descrição do cenário } \\
\hline $\begin{array}{c}\text { Não } \\
\text { SAAP }\end{array}$ & 0 & 0,3771 & $\begin{array}{l}\text { Situação em que não haveria SAAP na } \\
\text { regiâo, portanto toda a água consumida } \\
\text { seria proveniente do sistema público de } \\
\text { abastecimento. }\end{array}$ \\
\hline 2 & 50 & 38,1 & 0,2334 & $\begin{array}{l}\text { Considera que todas as residências } \\
\text { possuem SAAP, e levaram em conta a } \\
\text { viabilidade financeira; desconsidera, } \\
\text { situações em que o VPL seja negativo } \\
\text { para o prazo de 30 anos de uso do } \\
\text { SAAP. }\end{array}$ \\
\hline 3 & 80 & 43 & $\begin{array}{l}\text { Considera que todas as residências } \\
\text { possuem SAAP enão levaram em conta } \\
\text { a viabilidade financeira; considera, } \\
\text { situações em que o VPL seja negativo } \\
\text { para o prazo de 30 anos de uso do } \\
\text { SAAP; desvantajoso financeiramente. }\end{array}$ \\
\hline
\end{tabular}

(DOLABELLA, 2019)

Quadro 3: Parâmetros para simulação no EPANET

\begin{tabular}{|l|l|l|}
\hline & Propriedade & Valor \\
\hline \multirow{4}{*}{ Parâmetros hidráulicos } & Unidade de caudal & Litros por segundo (LPS) \\
\cline { 2 - 3 } & Fórmula de perda de carga & Darcy-Weisbach \\
\cline { 2 - 3 } & Densidade relativa & 1 \\
\cline { 2 - 3 } água & Viscosidade relativa & 1 \\
\hline \multirow{5}{*}{ Opções de tempo } & Unidade de massa & $\mathrm{mg} / \mathrm{L}$ \\
\cline { 2 - 3 } & Difusão relativa & 1 \\
\cline { 2 - 3 } & Tolerância de qualidade & 0,01 \\
\hline & Duração total da simulação & 168 horas (7 dias) \\
\cline { 2 - 3 } & Passo de cálculo hidráulico & 5 minutos \\
\cline { 2 - 3 } & Passo do cálculo de qualidade da água & 5 minutos \\
\cline { 2 - 3 } & Passo do tempo padrão & 1 hora \\
\cline { 2 - 3 } & Tempo de início do relatório & 24 horas \\
\hline Outros parâmetros & Cloro ETA & 1,25 mg/L \\
\hline
\end{tabular}

(adaptado de (DOLABELLA, 2019))

\subsection{Parâmetros de análise}

As normas brasileiras estabelecem parâmetros qualitativos e quantitativos em relação à água disponibilizada para a população por meio do sistema de abastecimento público, com o intuito de garantir adequado fornecimento de água, tanto quantitativamente, quanto qualitativamente. De entre esses parâmetros estão a velocidade (máxima e mínima), a pressão estática e dinâmica (máxima e mínima) e concentrações de CRL máxima e mínima. Neste estudo de caso foi considerada a injeção de $1,25 \mathrm{mg} / \mathrm{L}$ de $\mathrm{CRL}$ na ETA Lago Norte para as simulações, já que este foi o valor médio de injeção entre os anos de 2016 e 2018, conforme os dados da Companhia de abastecimento Saneamento Ambiental do Distrito Federal (Lourenço, 2017). Realizadas as simulações e obtidos os resultados, foram verificados os valores máximos e mínimos de velocidade, de pressão estática e dinâmica e de concentração de CRL em cada cenário. 
Figura 4: Padrão de consumo doméstico na rede

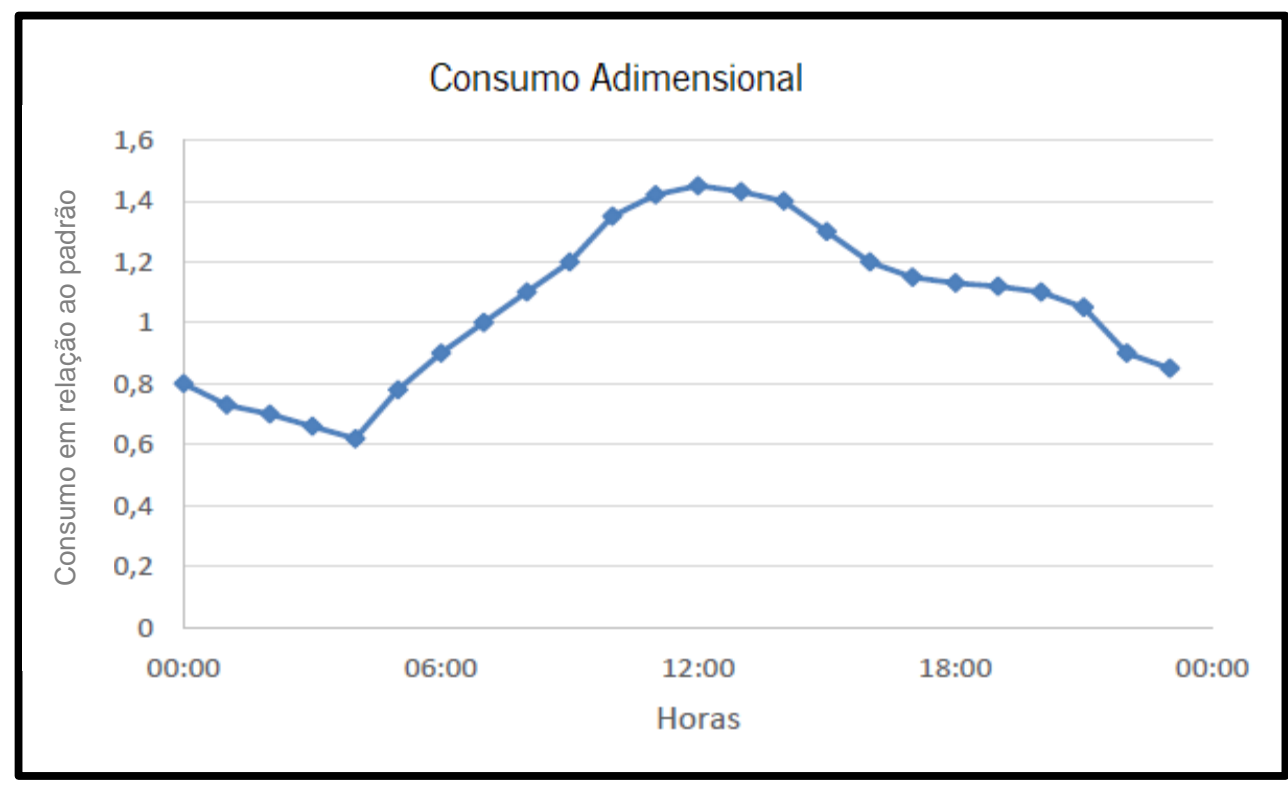

(LOURENÇO, 2017)

\section{ANÁLISE E DISCUSSÃO DOS RESULTADOS}

Apresenta-se de seguida a análise e discussão dos resultados, tendo por base a comparação entre as simulações dos três cenários, nos parâmetros velocidade, pressão e CRL. Apresentam-se igualmente propostas de gestão da rede, que possibilitem a verificação da sua conformidade com o normativo legal, de maneira a garantir a quantidade e qualidade do serviço prestado aos consumidores.

\subsection{Velocidade}

Observou-se a maior velocidade na área peninsular da RA Lago Norte, no cenário-base Cenário 1 - na tubulação v41, situada na porção esquerda da península, próxima ao RAPO (Reservatório Apoiado) Lago Norte. O maior valor da velocidade nesta tubulação obtida durante a simulação no Cenário 1 foi de $12,90 \mathrm{~m} / \mathrm{s}$, enquanto o menor valor foi igual a $5,51 \mathrm{~m} / \mathrm{s}$. É possível notar, pelo Gráfico 1, uma queda nos valores da velocidade quando há diminuição da utilização de água do sistema público de abastecimento em razão do aumento da utilização de SAAP. Além disso, é possível verificar uma diminuição na variação da velocidade entre os seus valores máximo e mínimo, ou seja, há uma maior regularidade no consumo ao longo do tempo. O valor médio das velocidades em cada cenário é mostrado na Tabela 1, onde se percebe uma queda relacionada ao menor consumo de água do sistema de fornecimento.

A tubulação com menor velocidade para o cenário-base foi a p9, e ficou praticamente estável, variando entre $0,00 \mathrm{~m} / \mathrm{s}$ e $0,01 \mathrm{~m} / \mathrm{s}$ neste cenário. Quando se avaliam os outros dois cenários, percebe-se que a velocidade ao longo de todo o período simulado foi constante e nula. A curva referente ao Cenário 2 no Gráfico 2 não aparece porque está sobreposta pela curva do Cenário 3 , já que possuem o mesmo valor em todo o período simulado. A Tabela 2 mostra a velocidade média na tubulação $\mathrm{p} 9$ em todos os três cenários, não havendo variação quando são comparados estes cenários, sendo o valor da velocidade média nulo.

Tabela 1: Velocidade média na tubulação v41 e variação da velocidade em relação ao Cenário 1

\begin{tabular}{lcc} 
& Velocidade média $(\mathbf{m} / \mathbf{s})$ & Variação \\
\hline Cenário 1 & 9,370 & - \\
\hline Cenário 2 & 5,800 & $-38.10 \%$ \\
\hline Cenário 3 & 5,340 & $-43.01 \%$ \\
\hline (DORABELLA, 2019) & &
\end{tabular}


Gráfico 1: Velocidade da água no trecho v41 para sete dias de simulação

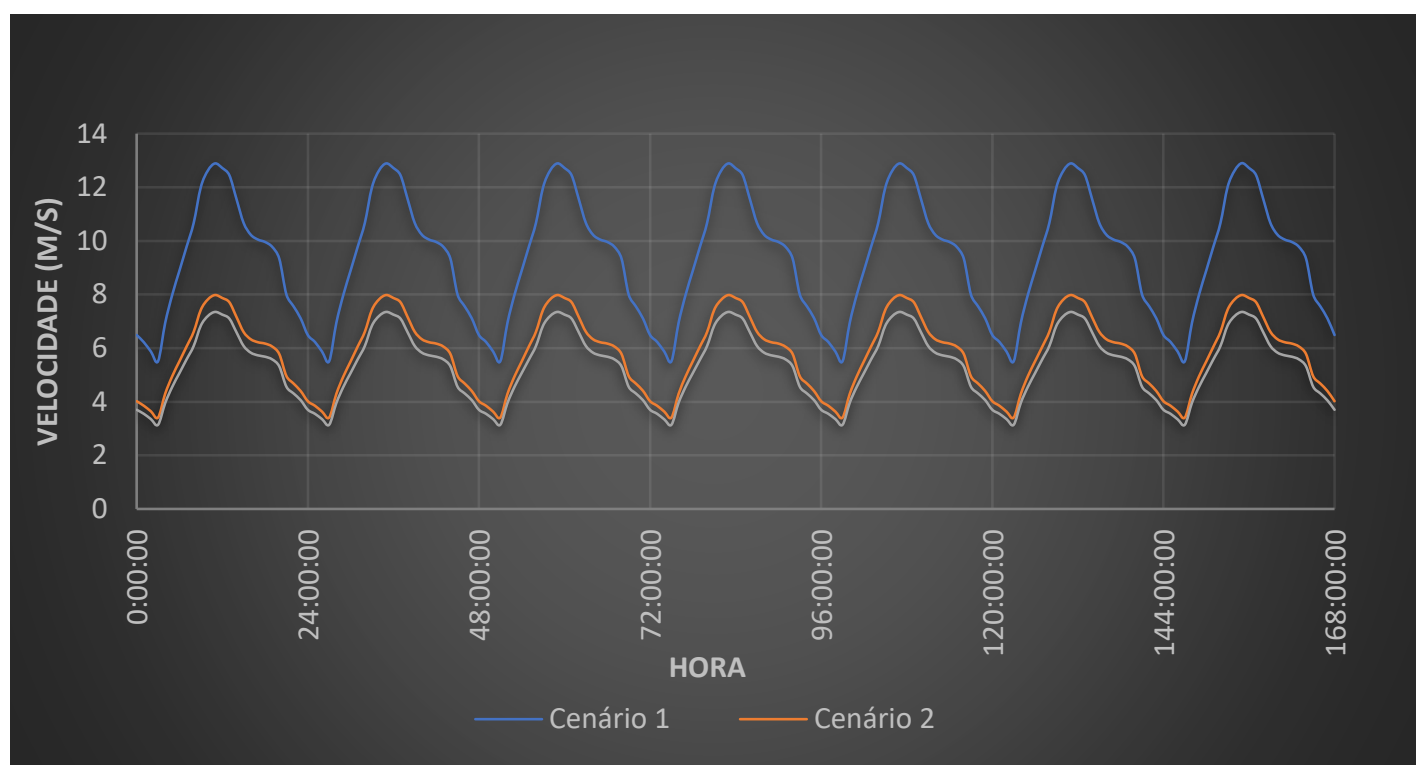

(DOLABELLA, 2019)

Gráfico 1: Velocidade da água no trecho p9 para os sete dias de simulação

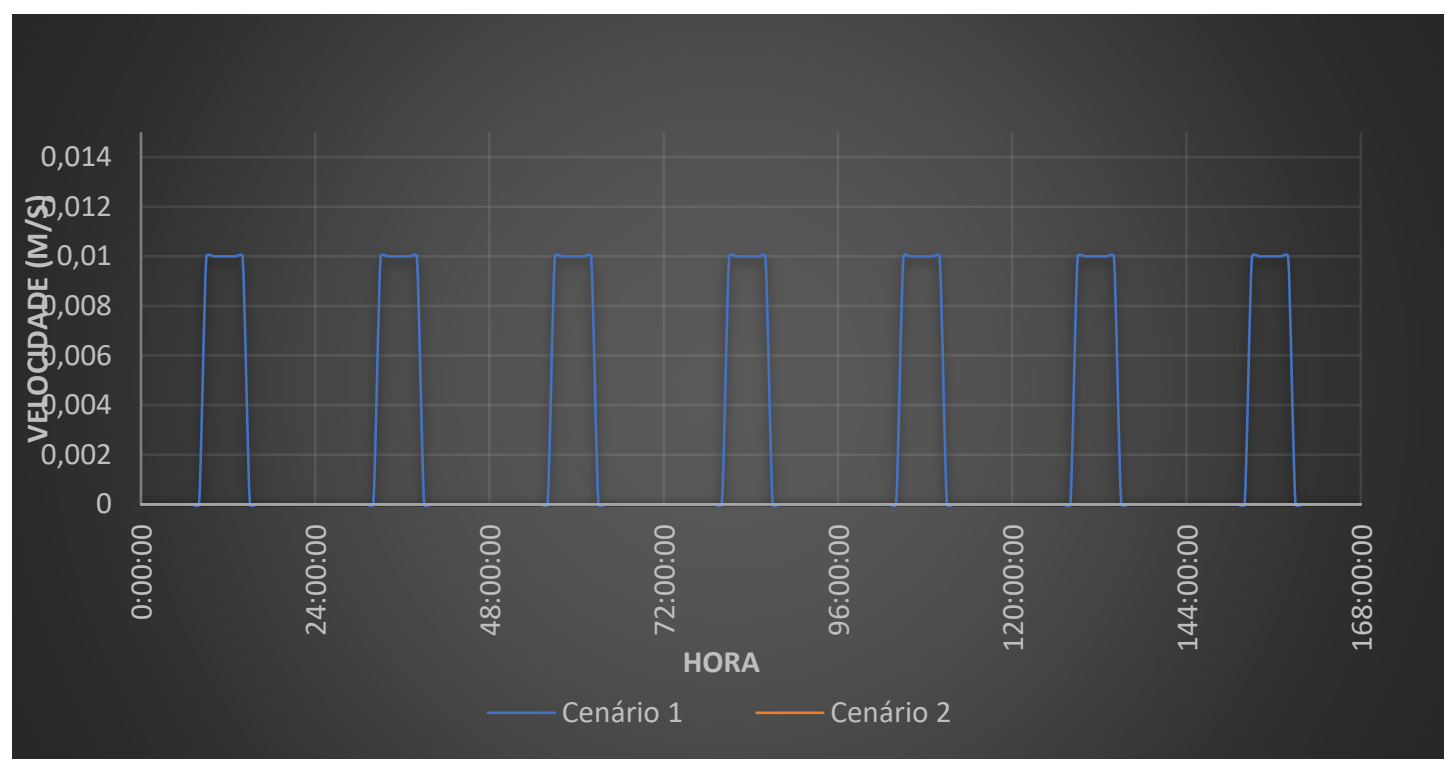

(DOLABELLA, 2019)

Tabela 2: Velocidade média na tubulação p9 e variação da velocidade em relação ao Cenário 1

Velocidade média $(\mathrm{m} / \mathrm{s}) \quad$ Variação

\begin{tabular}{llc}
\hline Cenário 1 & 0,000 & - \\
\hline Cenário 2 & 0,000 & $0,00 \%$ \\
\hline Cenário 3 & 0,000 & $0,00 \%$ \\
\hline (DOLABELLA, 2019) & &
\end{tabular}


Assim como na tubulação p9, a velocidade na maioria das tubulações foi inferior ao menor valor determinado pela ABNT NBR 12218 (2017) como valor mínimo a ser observado numa rede de abastecimento, que é igual a $0,4 \mathrm{~m} / \mathrm{s}$. Estes valores podem estar baixos devido às simplificações feitas na rede utilizada para realizar as simulações. A Figura 5 mostra os valores mínimos das velocidades, no Cenário 1 , obtidos por meio da simulação utilizando-se o EPANET. Os pontos pretos na Figura 5 representam nós sem consumo-base, devido a simplificação adotada na simulação.

Figura 5: Velocidades mínimas para o Cenário 1

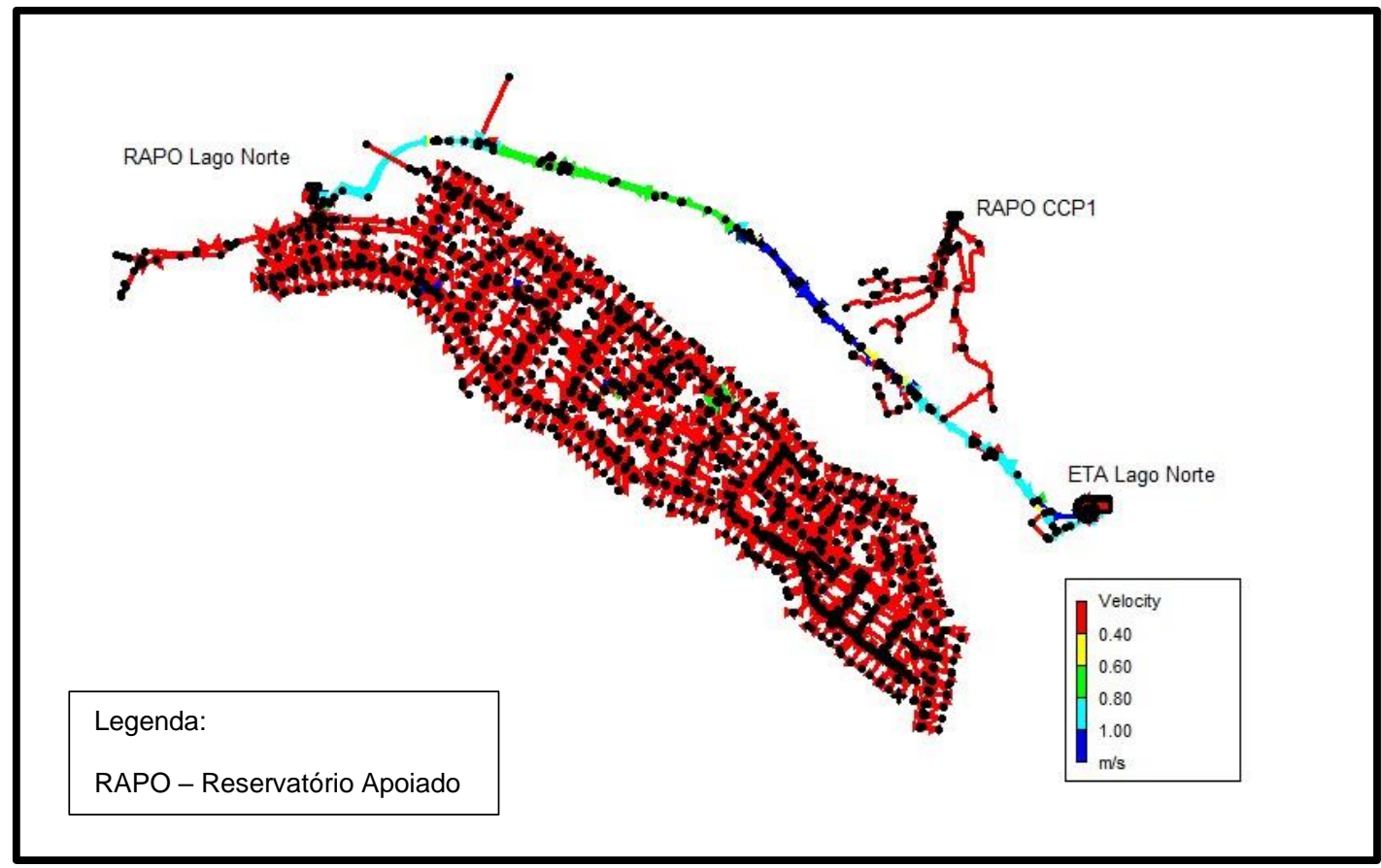

(DOLABELLA, 2019)

Quando se considera a média dos valores mínimos da velocidade de todos os trechos da rede, nota-se uma queda quando é maior a utilização de SAAP - e consequente queda da utilização de água do sistema público. A Tabela 3 mostra os valores das médias em cada cenário e a variação percentual em relação ao Cenário 1.

\subsection{Pressão}

Foram selecionados dois nós para que fossem analisadas as variações de pressão dinâmica em relação aos cenários determinados: o nó mais distante do reservatório RAPO Lago
Norte e o nó de maior cota topográfica. O nó n2221 é o nó mais afastado do reservatório RAPO Lago Norte, enquanto o nó de maior cota topográfica na área peninsular é o n7367. O Gráfico 3 mostra a variação da pressão no nó n2221 ao longo de sete dias, em que o aumento da utilização de SAAP provoca um aumento da pressão de dinâmica neste nó, além de diminuir a amplitude entre mínimos e máximos nesta situação. Apesar da variação da pressão em relação aos cenários, nota-se pela Tabela 4 que essa variação não é considerável para este nó, sendo a maior variação - entre os Cenários 1 e 3 - igual a 0,63\%.

Tabela 3: Média das velocidades mínimas em cada cenário e a variação em relação ao Cenário 1

\begin{tabular}{lcc}
\hline & $\begin{array}{c}\text { Média das velocidades mínimas } \\
(\mathbf{m} / \mathbf{s})\end{array}$ & Variação \\
\hline Cenário 1 & 0,111 & - \\
\hline Cenário 2 & 0,093 & $-16,19 \%$ \\
\hline Cenário 3 & 0,089 & $-19,04 \%$ \\
\hline (DOLABELLA, 2019) & & \\
\hline
\end{tabular}




\section{Gráfico 2: Pressão dinâmica no nó n2221 para sete dias}

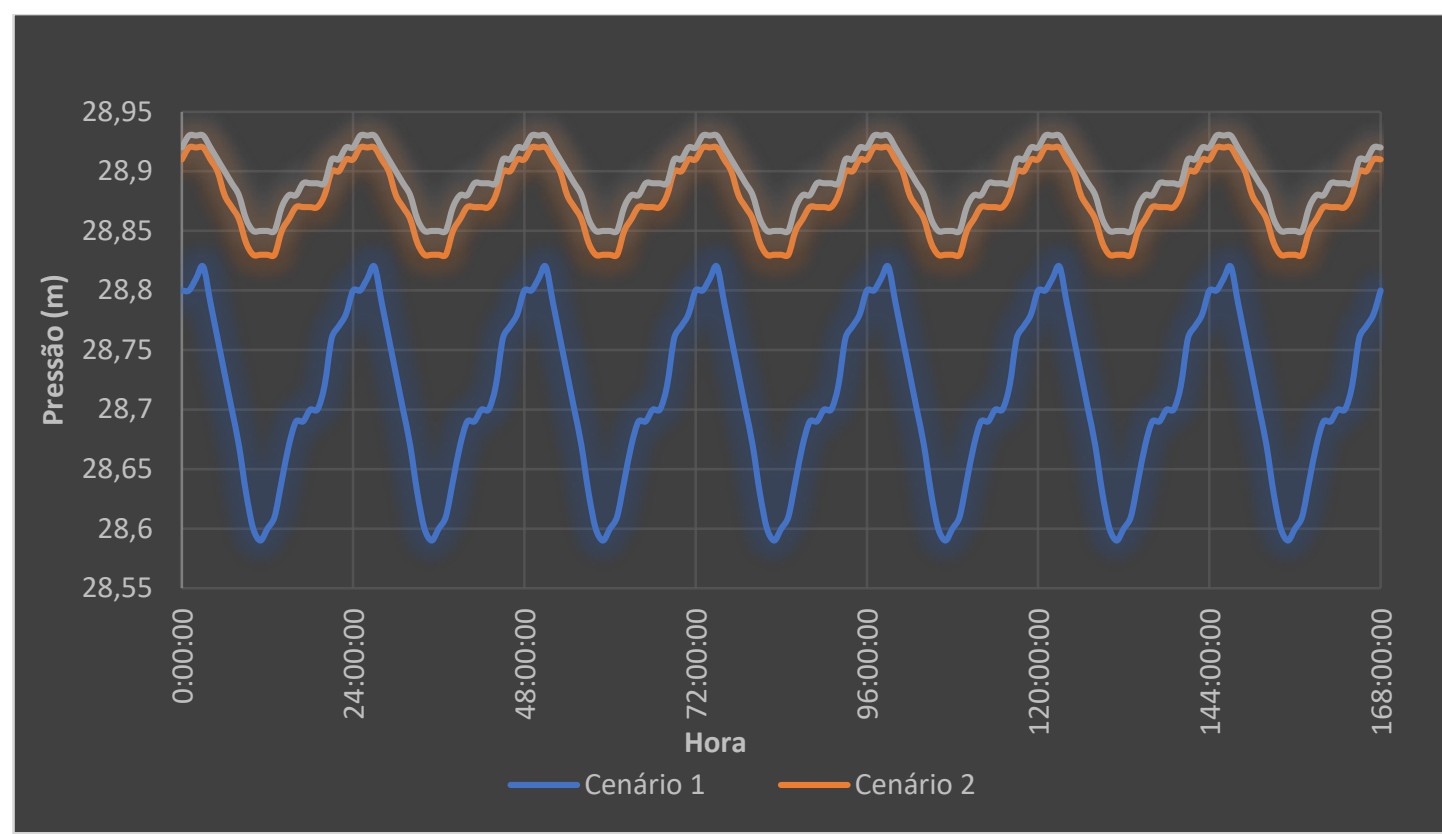

(DOLABELLA, 2019)

Tabela 4: Pressões dinâmicas médias para o nó n2221 e a variação em relação ao Cenário 1

\begin{tabular}{|lcc|}
\hline & $\begin{array}{c}\text { Pressões dinâmicas médias } \\
\text { (mca) }\end{array}$ & Variação \\
\hline Cenário 1 & 28,710 & - \\
\hline Cenário 2 & 28,876 & $0,58 \%$ \\
\hline Cenário 3 & 28,892 & $0,63 \%$ \\
\hline (DOLABELLA, 2019) & &
\end{tabular}

Assim como observado no nó n2221, o nó n7367 também sofre aumento da pressão dinâmica - Gráfico 4 - quando há aumento da utilização de SAAP e consequente diminuição do uso da água do sistema público de abastecimento, sendo a diferença entre os valores médios das pressões dinâmicas neste nó igual a 1,56\% quando comparados os Cenários 1 e 3 - Tabela 5. Apesar do aumento da pressão, nota-se que há uma menor amplitude entre os valores máximos e mínimos das pressões nos Cenários 2 e 3 , o que exige um controle menos rigoroso em relação às variações das pressões nas tubulações

Tabela 5: Pressões dinâmicas médias para o nó n7367 e a variação em relação ao Cenário 1

Pressões dinâmicas médias (mca)

\begin{tabular}{llc}
\hline Cenário 1 & 53,219 & - \\
\hline Cenário 2 & 53,976 & $1,42 \%$ \\
\hline Cenário 3 & 54,051 & $1,56 \%$ \\
\hline (DOLABELLA, 2019) & &
\end{tabular}


Gráfico 3: Pressão dinâmica no nó n7367 para sete dias

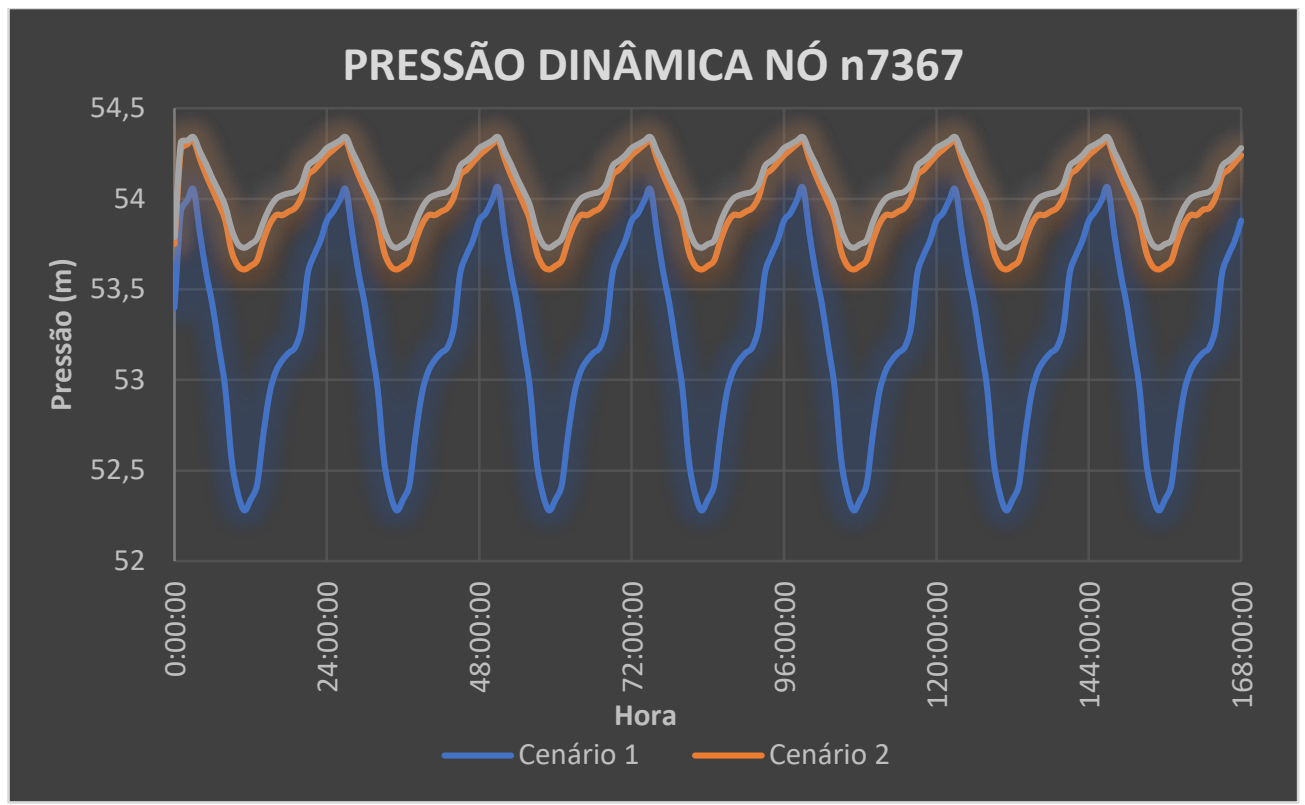

(DOLABELLA, 2019)

Para verificar se o aumento de pressão não havia ocorrido apenas pontualmente nos nós selecionados, foram calculadas as médias das pressões dinâmicas máximas para toda a rede de abastecimento, verificando-se globalmente o aumento das pressões na rede quando há diminuição do uso da água do sistema público de abastecimento em razão do aumento do uso de SAAP, conforme a Tabela 6 . As variações foram calculadas em relação ao Cenário 1 , quando não há utilização de SAAP. Nota-se que, assim como aconteceu nos nós n2221 e n7367, a variação média das pressões dinâmicas máximas foi pequena, não sendo maior do que $1,51 \%$.

Tabela 6: Média das pressões dinâmicas máximas e variação em relação ao Cenário 1

\begin{tabular}{lcc}
\hline & $\begin{array}{c}\text { Média das pressões dinâmicas } \\
\text { (mca) }\end{array}$ & Variação \\
\hline Cenário 1 & 31,165 & - \\
\hline Cenário 2 & 31,383 & $0,95 \%$ \\
\hline Cenário 3 & 31,427 & $1,51 \%$ \\
\hline (DOLABELLA, 2019) & &
\end{tabular}

\subsection{Qualidade (CRL)}

Com o aumento do uso de SAAP e consequente diminuição do uso da água proveniente do sistema público de abastecimento, a água presente na rede de abastecimento tende a ficar por um espaço de tempo maior a circular nessa rede, aumentando, portanto, a idade da água, o que leva a uma diminuição de CRL na rede, podendo haver diminuição da qualidade da água fornecida à população.
Para analisar os valores de CRL na rede de abastecimento comparando-se os três cenários definidos, foi selecionado o nó com a maior idade da água - n782, pois este nó representa a pior situação em relação à concentração mínima de CRL. O Gráfico 5 mostra o aumento da idade da água no nó n782 nos Cenários 2 e 3, enquanto o Gráfico 6 mostra a diminuição de CRL neste nó.

Apesar da diminuição da concentração de CRL nos Cenários 2 e 3 em relação ao Cenário 1, as concentrações continuam dentro dos limites estabelecidos pela Portaria 2914 (MINISTÉRIO 
DA SAÚDE DO BRASIL, 2011), com exceção apenas nas primeiras horas, que representam o enchimento da rede. A Tabela 7 mostra a concentração média de CRL no nó $n 782$, além da variação de $\mathrm{CRL}$ em relação ao cenário-base Cenário 1. Nesta situação, percebe-se que a diminuição do consumo de água da rede pública influenciada pelo aumento do uso de SAAP acarretou uma diminuição considerável de $\mathrm{CRL}$ para este nó, tendo chegado a 16,39\% de redução da concentração no Cenário 3 em relação ao Cenário 1.

\section{Gráfico 4: Idade da água para o nó n782 ao longo de sete dias}

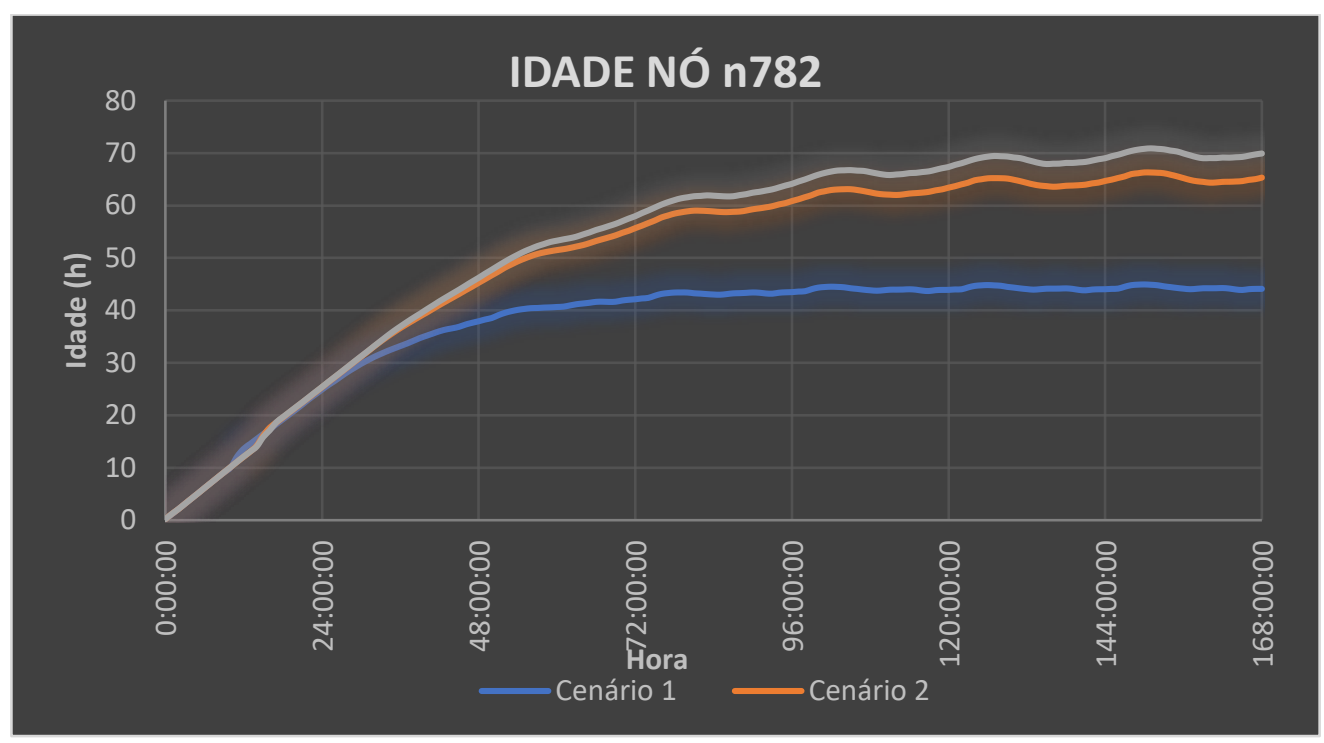

(DOLABELLA, 2019)

Gráfico 5: CRL no nó n782 para sete dias

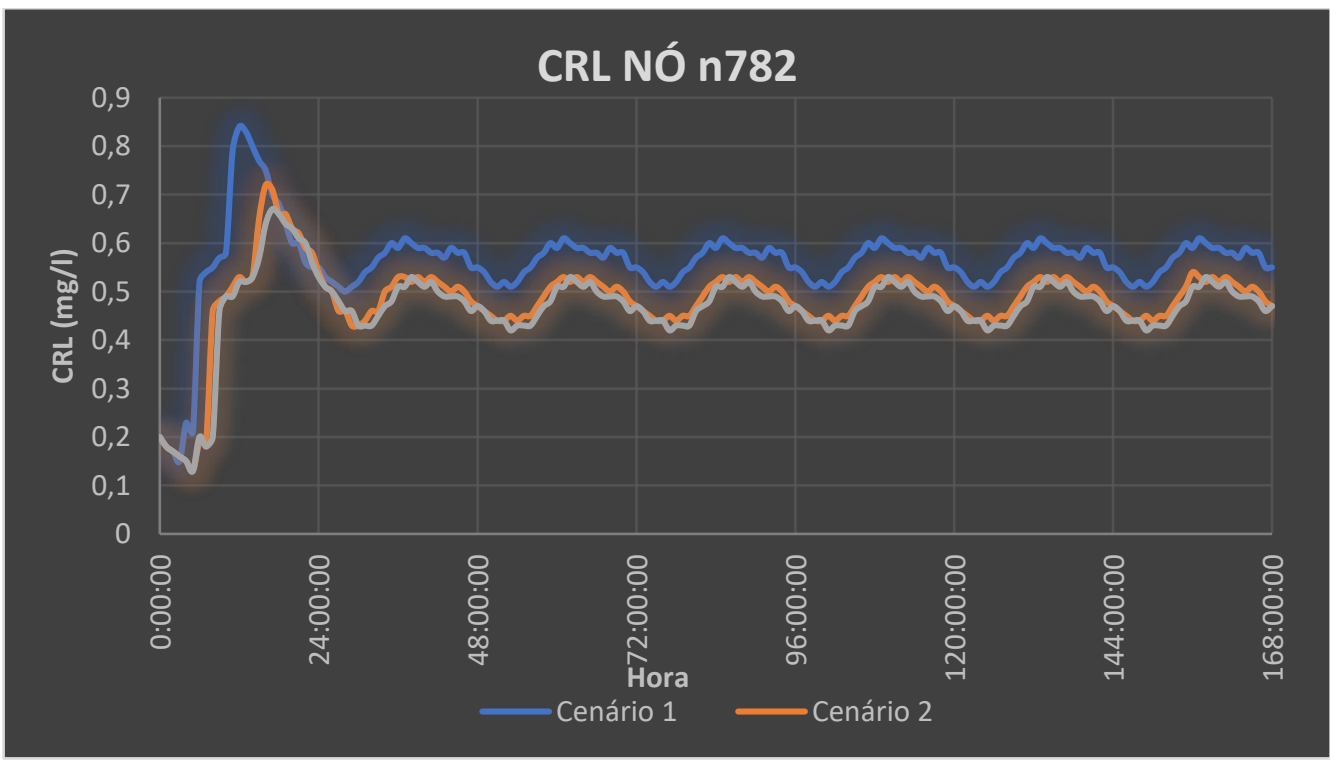

(DOLABELLA, 2019)

Tabela 7: CRL médio no nó n782 e variação em relação ao Cenário 1

CRL médio (mg/L) Variação

\begin{tabular}{llc}
\hline Cenário 1 & 0,560 & - \\
\hline Cenário 2 & 0,482 & $-13,86 \%$ \\
\hline Cenário 3 & 0,468 & $-16,39 \%$ \\
\hline
\end{tabular}


A Tabela 8 mostra que a redução de $C R L$ não aconteceu apenas no nó n782, tendo decrescido também em relação à média das concentrações mínimas dos nós de toda a rede. Esta redução chega a $10,78 \%$ quando se comparam as médias dos valores mínimos da concentração de CRL nos Cenários 1 e 3 , o que mostra a necessidade de se ter atenção ao potencial de redução da qualidade da água fornecida pelo sistema público, já que a utilização de SAAP é cada vez maior no DF, principalmente após o racionamento de água ocorrido entre os anos de 2016 e 2017, que levou muitas pessoas a procurar buscar formas alternativas de abastecimento de água, especialmente em regiões em que há jardins e piscinas, como é o caso do Lago Norte.

Tabela 8: Média de CRL mínimo e variação em relação ao Cenário 1

\begin{tabular}{lcc}
\hline & $\begin{array}{c}\text { Média de CRL mínimo } \\
\text { (mg/L) }\end{array}$ & Variação \\
\hline Cenário 1 & 0,480 & - \\
\hline Cenário 2 & 0,437 & $-9,07 \%$ \\
\hline Cenário 3 & 0,429 & $-10,78 \%$ \\
\hline (DOLABELLA, 2019) & &
\end{tabular}

\subsection{Propostas de gestão dos serviços de abastecimento de água na rede pública}

Os resultados obtidos e a sua comparação com o normativo legal em vigor permitem que se definam propostas que possibilitem melhorias na rede pública de abastecimento de água. Assim, apresentam-se abaixo, de forma sucinta, as ações a desenvolver de forma a possibilitar que a rede de abastecimento do Lago Norte se mantenha em funcionamento, apesar dos impactos que a adoção de SAAP poderiam ter na velocidade mínima, pressão e CRL.

Velocidade mínima. Para prevenir a existência de velocidades mínimas inferiores às regulamentares, as tubulações onde tal se verifica deveriam ser dotadas de descargas de fundo instaladas no seu ponto mais baixo, e as rotinas de manutenção da rede de abastecimento deveriam prever o esvaziamento periódico dessas tubulações.

Pressão. Como a norma brasileira NBR 12218 (ABNT, 2017) determina que as pressões estáticas não podem exceder os $500 \mathrm{kPa}$ e a rede simplificada de abastecimento de água do Lago Norte, utilizada neste trabalho, não possui elementos visando a redução das pressões, propõe-se a inclusão de válvulas redutoras de pressão (VRP) na rede, para que as pressões estáticas máximas sejam cumpridas. Assim, a (DOLABELLA, 2019) apresenta as pressões estáticas nos nós após a possível colocação de 64
VRP. A localização detalhada das VRP pode ser encontrada no anexo D de Dolabella (2019). Como as pressões estáticas não variam com a mudança dos cenários, foi feita a simulação apenas para o Cenário 1. Os trechos em que as pressões são mais elevadas não são diretamente ligados ao consumidor final, nem às tubulações secundárias, não sendo definidos, portanto, valores máximos ou mínimos de pressão, desde que se garanta a estabilidade estrutural e a segurança sanitária (ABNT, 2017). Como há um período de estiagem na região, há um período em que a utilização dos SAAP seria maior pois, além dos usos internos (lavagem de roupa e descarga de bacias sanitárias) há uma grande utilização de água para irrigação de jardins e áreas verdes. Com o aumento do uso da água proveniente dos SAAP, haveria um aumento das pressões estáticas, sendo este mais um motivo para a colocação de VRP na rede. No entanto, como a análise apresentada não pretende analisar a curva de consumo de água do SAAP ao longo do ano, em função da temperatura média do ar $e$ da pluviosidade e consequente quantidade de água disponível no interior do reservatório do SAAP, a simulação relativa a este período de estiagem não foi efetuada.

CRL. No caso do Cenário 3, foram adicionados pontos de cloragem em determinados nós, de forma a que a rede não tivesse nós com concentração menor do que $0,2 \mathrm{mg} / \mathrm{L}$ de $C R L$, conforme a Tabela 9. Apesar disso alguns nós 
continuaram com concentração de cloro menor do que $0,2 \mathrm{mg} / \mathrm{L}$, tanto em razão da simplificação da rede, quanto pela existência de hidrantes, onde a água tende a ficar parada, aumentando consequentemente a idade da água nesses pontos, o que afeta a concentração de CRL. As
Figuras 7 e 8 mostram as concentrações mínimas de CRL na rede no Cenário 3 antes e após a adição dos pontos de cloragem (desconsiderando as primeiras 24 horas, em que a simulação está a convergir), respectivamente.

Figura 6: Pressões estáticas após colocação de válvulas redutoras de pressão - Cenário 1

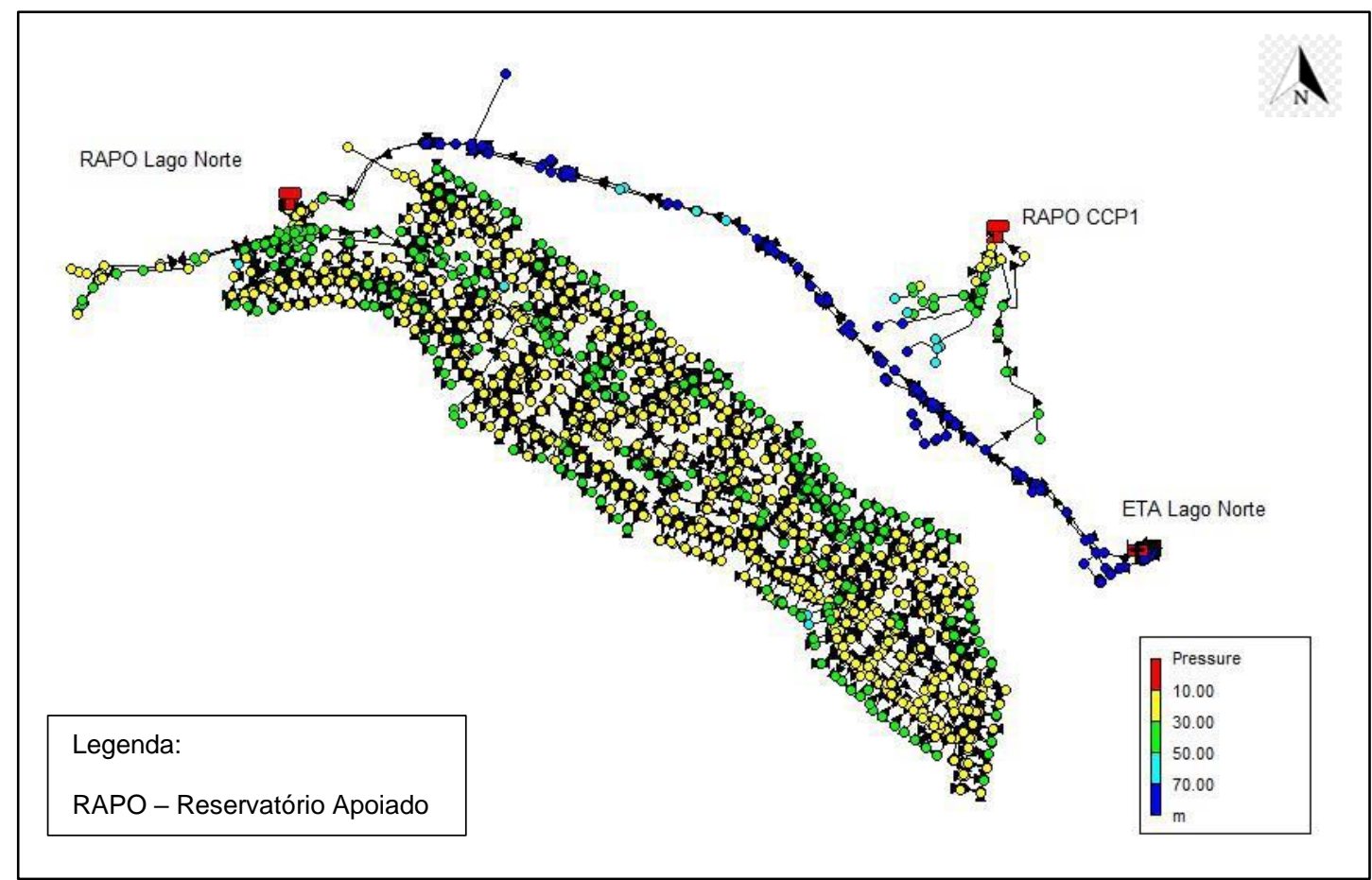

(DOLABELLA, 2019)

Tabela 9: Pontos de cloragem adicionados e respectiva concentração de injeção

\begin{tabular}{cc}
\hline Nó & Concentração (mg/L) \\
\hline $\mathbf{n 2 9 7}$ & 1,00 \\
\hline $\mathbf{n} 556$ & 1,00 \\
\hline $\mathbf{n} 1759$ & 1,00 \\
\hline $\mathbf{n} 2081$ & 0,75 \\
\hline $\mathbf{n} 3589$ & 0,75 \\
\hline $\mathbf{n} 4185$ & 0,75 \\
\hline $\mathbf{n 4 1 9 4}$ & 0,75 \\
\hline $\mathbf{1 2}$ & 1,00 \\
\hline
\end{tabular}

(DOLABELLA, 2019) 
Figura 7: CRL no Cenário 3 antes da inserção de pontos de cloragem

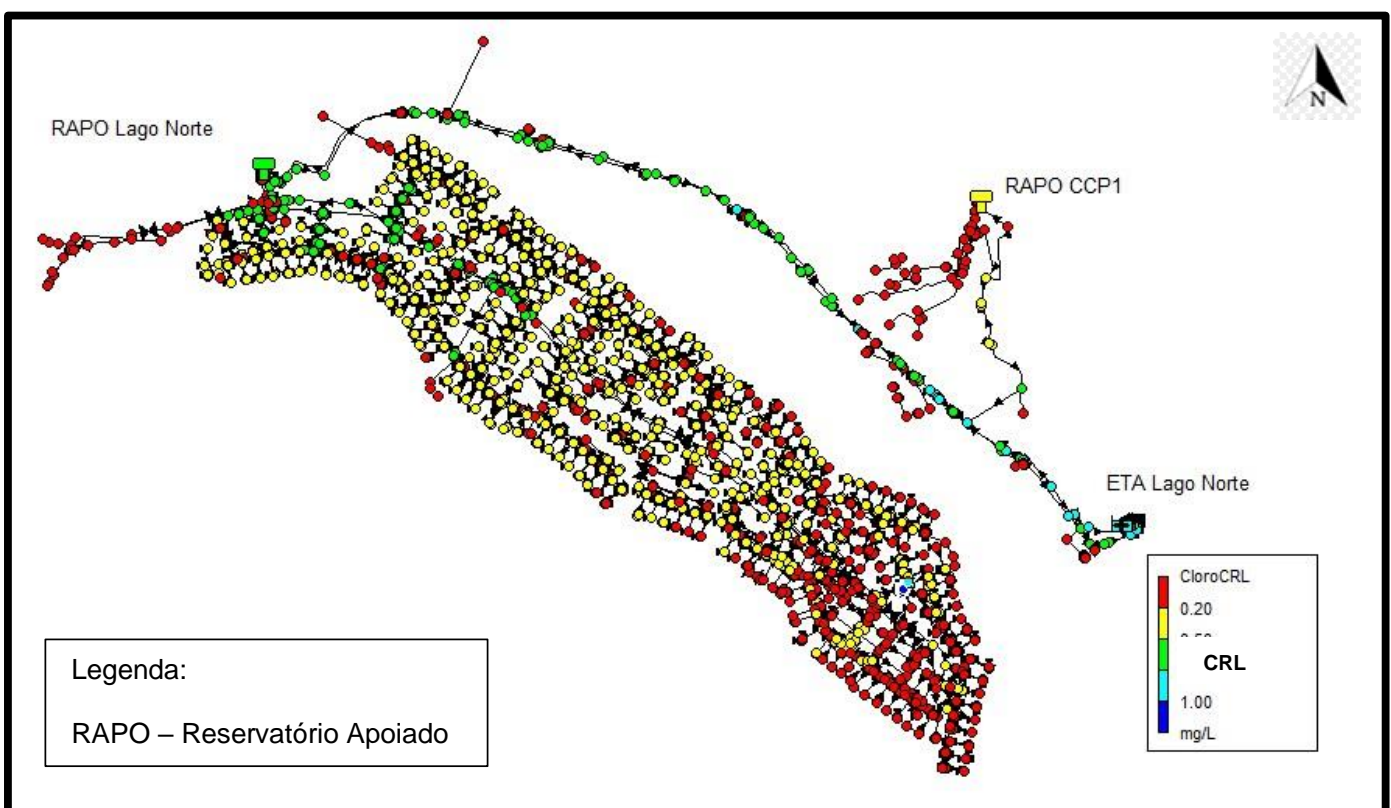

(DOLABELLA, 2019)

Figura 8: CRL no Cenário 3 após a inserção de pontos de cloragem

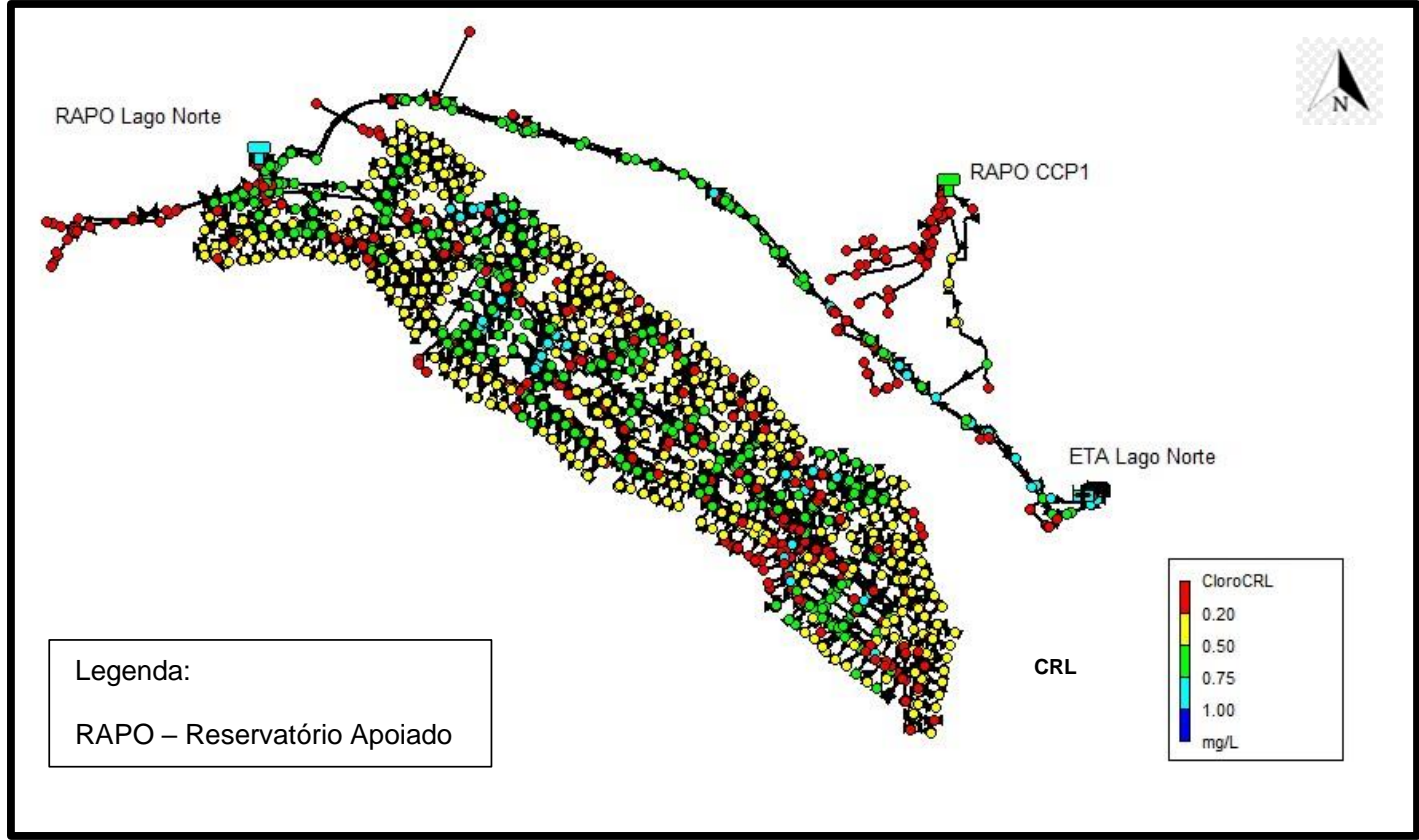

(DOLABELLA, 2019)

\section{CONCLUSÕES}

A possível utilização de SAAP, especialmente em regiões com elevado consumo de água, como o Lago Norte - DF, Brasil, foi estudada através de simulações hidráulicas e de qualidade. Os três cenários, correspondentes a uma redução de $43 \%$, $38,1 \%$ de água da rede pública de abastecimento e à não utilização de SAAP, mostram que quanto maior a utilização de SAAP, menor é o valor da velocidade média nas tubulações.

A simulação permitiu identificar as tubulações com valores de velocidade mínima inferiores ao mínimo regulamentar, nas quais devem adoptadas descargas de fundo e definido um programa de operação e manutenção da rede, que preveja a sua descarga periódica. O aumento do uso de SAAP levou igualmente ao aumento da pressão dinâmica nos nós da rede. A simulação permitiu identificar a necessidade de adicionar 64 VRP à 
rede. Para aprimorar o estudo da influência dos SAAP em relação ao $C R L$ simulou-se a colocação de pontos de cloragem em diferentes locais da rede, analisando-se a necessidade de alteração da cloração em decorrência do maior ou menor uso dos SAAP. No total foram considerados 10 possíveis pontos de cloragem, com concentrações de $0,75 \mathrm{mg} / \mathrm{L}$ ou $1 \mathrm{mg} / \mathrm{L}$.

Os resultados apresentados permitem concluir que foi possível avaliar a influência que o aumento do uso de SAAP poderia ter sobre as infraestruturas de abastecimento de água potável num bairro com grande potencial para o uso deste tipo de sistema - o Lago Norte em Brasília, no Distrito Federal - Brasil. A análise dos impactos de âmbito técnico, causados pelo uso em escala de sistemas alternativos de abastecimento de água, possibilita fornecer aos gestores de redes de abastecimento público de água informação para que sejam tomadas as melhores opções de operação e manutenção. Em particular, os resultados apresentados alertam para a necessidade de monitorização constante de uma rede que esteja sujeita a variações acentuadas de consumo, decorrentes da adopção generalizada da utilização de SAAP, e consequentemente permitem aos gestores da rede de abastecimento de água tomar as decisões necessárias para continuar a garantir a qualidade do serviço nessas circunstâncias. Conclui-se assim que este tipo de análise constitui uma importante e muito útil ferramenta de gestão de redes de abastecimento público de água.

\section{REFERÊNCIAS}

ABNT. "ABNT NBR 12218 - Projeto de rede de distribuição de água para abastecimento púlbico Procedimento", 2017.

ABU-ZREIG, M., HAZAYMEH, A., SHATANAWI, M. "Evaluation of residential rainfall harvesting systems in Jordan", Urban Water Journal, v. 10, n. 2, p. 105-111, 2013. DOI: 10.1080/1573062X.2012.709255. Disponível em: https://doi.org/10.1080/1573062X.2012.709255.

ADMINISTRAÇÃO REGIONAL DO LAGO NORTE. Mapa Base do Lago Norte. 2016. Disponível em: http://www.lagonorte.df.gov.br/wp-

conteudo//uploads/2016/07/Mapa_Base_lago_norte.jpg . Acesso em: 12 mar. 2021.

AGÊNCIA BRASÍLIA. Água do Lago Paranoá vai poupar ainda mais os Sistemas Descoberto e Santa Maria. 2018. Disponível em: https://www.agenciabrasilia.df.gov.br/2018/01/15/aguado-lago-paranoa-vai-poupar-ainda-mais-os-sistemasdescoberto-e-santa-maria/. Acesso em: 27 abr. 2021.
AMERICAN WATER WORKS ASSOCIATION (AWWA). Residential End Uses of Water. . Denver, CO, [s.n.], 1999.

ANTONIOU, G., KATHIJOTES, N., SPYRIDAKIS, D. S., et al. "Historical development of technologies for water resources management and rainwater harvesting in the Hellenic civilizations", International Journal of Water Resources Development, v. 30, n. 4, p. 680-693, 2 out. 2014. DOI: 10.1080/07900627.2014.900401. Disponível em: https://doi.org/10.1080/07900627.2014.900401.

DEITCH, M. J., FEIRER, S. T. "Cumulative impacts of residential rainwater harvesting on stormwater discharge through a peri-urban drainage network", Journal of Environmental Management, v. 243, p. 127-136, 1 ago. 2019. DOI: 10.1016/j.jenvman.2019.05.018. .

DOLABELLA, G. Análise da Influência do Aproveitamento de Águas Pluviais numa Rede Pública de Abastecimento de Água. O caso do Lago Norte, Brasília-DF Brasil. 2019. 84 f. Universidade do Minho, 2019.

ENVIRONMENT AGENCY. Harvesting rainwater for domestic uses : an information guide. . Bristol, [s.n.], 2010. Disponível em: www.envoronmentagency.gov.uk.

GONÇALVES, R. F. "Uso racional de água e energia PROSAB [Integrated water managemant and energy Sanitation Research Program]", p. 1-354, 2009. .

GRANDET, C., BINNING, P. J., MIKKELSEN, P. S., et al. "Effects of rainwater harvesting on centralized urban water supply systems", Water Science and Technology: Water Supply, v. 10, n. 4, p. 570-576, 1 set. 2010. DOI: 10.2166/ws.2010.172. Disponível em: https://dx.doi.org/10.2166/ws.2010.172.

INMET. Banco de Dados Meteorológicos para Ensino e Pesquisa. 2019. Disponível em: http://www.inmet.gov.br/projetos/rede/pesquisa/inicio.p hp. Acesso em: 08 abr. 2021.

JUUTI, P. S., KATKO, T. S., VUORINEN, H. S. Environmental History of Water. 1. ed. Cornwall, IWA Publishing, 2007. Disponível em: https://books.google.pt/books?id=pZDbCwAAQBAJ\&pg $=$ PA24\&dq=Juuti+rainwater\&hl=pt-

PT\&sa $=X \&$ ved=0ahUKEwibzp3GtZDgAhXQDGMBHVU $c C 4 s Q 6 A E I K z A A \# v=$ onepage $\& q=J u u t i$ rainwater\& $f=f a l s e$.

LOURENÇO, I. Análise do Decaimento do Cloro Residual Livre com Contaminação Pontual na Rede de Distribuição de Água do LAgo Norte - DF em Situação de Intermitência. 2017. 112 f. Universidade de Brasília, 2017.

MINISTÉRIO DA SAÚDE DO BRASIL. Portaria de Consolidação $n^{\circ}$ 5, de 3 de outubro de 2017.pdf Português (Brasil). 2017. Disponível em: https://www.gov.br/agricultura/ptbr/assuntos/inspecao/produtos-vegetal/legislacao- 
1/biblioteca-de-normas-vinhos-e-bebidas/portaria-deconsolidacao-no-5-de-3-de-outubro-de-2017.pdf/view. Acesso em: 9 maio 2021.

MINISTÉRIO DA SAÚDE DO BRASIL. Portaria n 2914 de 12 de dezembro de 2011 - Procedimento de controle e de vigilância da qualidade da água para consumo humano e seu padrão de potabilidade. $2011 . \quad$ Disponível em: http://www.saude.mg.gov.br/images/documentos/PORT ARIA No- 2.914, DE 12 DE DEZEMBRO DE 2011.pdf. Acesso em: 01 abr. 2021.

MUÑOZ, C. C. Viabilidad técnica y financiera de un sistema hidrosanitario para el aprovechamiento de aguas pluviales. Análisis comparativo entre Colombia y Portugal. 2017. Universidade do Minho, 2017.

NAÇÕES UNIDAS. Objetivos de Desenvolvimento Sustentável. 2015. Disponível em: https://www.unric.org/pt/17-objetivos-de-

desenvolvimento-sustentavel. Acesso em: 22 abr. 2021.

NAÇÕES UNIDAS. Relatório mundial das Nações Unidas sobre desenvolvimento dos recursos hídricos. . [S.I: s.n.], 2016. Disponível em: http://unesdoc.unesco.org/images/0024/002440/2 44040por.pdf. Acesso em: 05 mai. 2021.

NAÇÕES UNIDAS. Relatório mundial das Nações Unidas sobre desenvolvimento dos recursos hídricos 2018: soluções baseadas na natureza para a gestão da água. . Paris, [s.n.], 2018. Disponível em: www.unesco.org/water/wwap.

OCDE. OECD Environmental Outlook, Books / OECD Environmental Outlook / 2012:The Consequences of Inaction. [S.I: s.n.], 2012. Disponível em: http://www.oecdilibrary.org.gate2.library.Ise.ac.uk/environment/oe cd-environmental-outlook-to-

2050_9789264122246-en. Acesso em: 08 mai. 2021.

SACADURA, F. O. M. O. Análise de sistemas de aproveitamento de água pluvial em edifícios. 2011. Universidade Nova de Lisboa, 2011. Disponível em: http://hdl.handle.net/10362/6153.

SANT'ANA, D., MEDEIROS, L., ALVARES, K. Aproveitamento de Águas Pluviais e Reúso de Águas Cinzas em Edificações - Princípios de políticas tarifárias baseados em uma análise de viabilidade ambiental e econômica. . BrasíliaDF, [s.n.], 2017. Disponível em: http://www.adasa.df.gov.br/images/storage/area de_atuacao/abastecimento_agua_esgotamento_s anitario/regulacao/reuso_aguas_cinza_aproveita mento_aguas_pluviais/reusodf_1_politicas_tarifari as.pdf.

TEXAS COMMISSION ON ENVIRONMENTAL QUALITY. Harvesting , Storing , and Treating Rainwater for Domestic Indoor Use. Austin, [s.n.], 2007. Disponível em: www.tceq.state.tx.us/publications.

VIEIRA, J. Água e Saúde Pública. 1ª ed. Lisboa, Edições Sílabo, 2018.

WATER, T., BOARD, D. "The Texas Manual on Rainwater Harvesting", Development, v. 51, n. 7, p. 1-5, 2005. DOI: 10.1007/s10350-008-9244-1. Disponível em: http://www.twdb.state.tx.us/publications/reports/R ainwaterHarvestingManual_3rdedition.pdf.

WIKIPEDIA. Lago Norte. 2019. Disponível em: https://pt.wikipedia.org/wiki/Lago_Norte. Acesso em: 13 mar. 2021. 